\title{
Dynamics of global business cycle interdependence
}

\author{
Lorenzo Ductor $^{\mathrm{a}}$, Danilo Leiva-Leon ${ }^{\mathrm{b}, *}$ \\ ${ }^{a}$ Middlesex University London, United Kingdom \\ ${ }^{\mathrm{b}}$ Central Bank of Chile,Chile
}

\section{A R T I C L E I N F O}

\section{Article history:}

Received 14 April 2015

Received in revised form 7 July 2016

Accepted 7 July 2016

Available online 14 July 2016

\section{JEL classification}

C34

C45

E32

\section{Keywords:}

Business cycles

Markov-switching

Network analysis

Model uncertainty

\begin{abstract}
A B S T R A C T
In this paper, we provide a comprehensive analysis of the time-varying interdependence among the economic cycles of the major world economies during the post-Great Moderation period. We document a significant increase in the global business cycle interdependence occurred in the early 2000s. Such increase is mainly attributed to the emerging market economies, since their business cycles became more synchronized with the rest of the world around that time. Moreover, we find that the increase in global interdependence is highly related to decreasing differences in sectoral composition among countries.
\end{abstract}

(c) 2016 The Authors. Published by Elsevier B.V. This is an open access article under the CC BY-NC-ND license (http://creativecommons.org/licenses/by-nc-nd/4.0/).

\section{Introduction}

Recent decades have witnessed increased globalization of the world economy associated with economic and financial integration among countries. On the one hand, economic and financial integration may exert a positive effect on economic growth by reducing transaction costs, ameliorating information asymmetries, facilitating specialization among countries according to their comparative advantage, and facilitating the transfer of resources across countries. On the other hand, economic and financial integration, which is associated with high business cycle interdependence, may increase

\footnotetext{
is We thank Charles Engel and two anonymous referees for their useful comments and suggestions that helped to improve significantly this article. We are grateful to Ron Alquist, Michael Ehrmann, Daryna Grechyna, and Robert Lavigne; seminar participants at the Bank of Canada, Central Bank of Chile, Auckland University of Technology, and Massey University; and participants of the 24th New Zealand Econometrics Study Group and the 2014 Southern workshop in Macroeconomics for their valuable comments. Simon Richards provided excellent research assistance. Supplementary material of this paper can be found at https://sites.google.com/site/daniloleivaleon/ global-business-cycles.

* Corresponding author.

E-mail addresses: 1.ductorgomez@mdx.ac.uk (L. Ductor), dleiva@bcentral.cl (D. Leiva-Leon).
}

global systemic risk, since country-specific shocks can be rapidly transmitted to other economies.

The degree of interdependence between the economy of a given country and the rest of the world may also experience significant changes over time due to uncountable number of reasons, such as economic unions, trade agreements, financial liberalization, just to mention a few. Therefore, understanding the patterns and mechanisms governing world economic interdependence is crucial for policy makers and investors to evaluate the degree of exposure that a given country has to external shocks.

Several studies have focused on assessing changes in the degree of global business cycle synchronization. Kose et al. (2012) and Kose et al. (2003) focus on assessing the variability of country GDP growth explained by common components, they use linear dynamic factor models (DFM) to assess changes in synchronization by splitting the data into sub-samples. Del Negro and Otrok (2008) proceed in a similar way, but rely on time-varying parameters DFM to assess endogenous changes. Since one of the defining characteristics of the business cycle is its asymmetric nature, Burns and Mitchell (1946), the degree and speed of the business cycle shocks transmission may also depend on the economic phase that a given country faces (recession or expansion). To account for such nonlinear dynamics, other studies have focused on assessing the bilateral synchronization between cycles, defined as the alternation of expansionary and 
recessionary phases, see Harding and Pagan (1999) and Camacho et al. (2008). Information about bilateral synchronization is useful to identify groups of countries following similar business cycle patterns and to explain those patterns. Although the frameworks used in these studies provide an overall assessment of the interdependence between the economic cycles of a set of countries, such assessment is constant over time. Therefore, to identify potential changes in the interdependence of cycles the sample has to be splitted on a given date, which is usually controversial.

Another important issue is assessing the main determinants of business cycle interdependence. To address this issue most of the studies in the literature have used the correlation of GDP growth (or de-trended GDP) between pairs of countries as a measure of business cycle synchronization and relied on cross-section analysis to assess its main determinants. Previous studies find a positive relationship between business cycle synchronization and trade (Imbs, 2004), financial integration (Frankel and Rose, 1998), currency unions (Rose and Engel, 2002), sectoral composition, public sector size (Camacho et al., 2008), institutional environment and cultural factors (Altug and Canova, 2012). Also the determinants may vary across sets of countries. Imbs (2006) and Clark and Van Wincoop (2001) find high synchronization between financially open developing countries and the G7. Canova and Ciccarelli (2012) and Canova and Schlaepfer (2013) analyze business cycle interdependence among Mediterranean countries and find that traditional transmission channels, such as trade and financial integration, are not very important determinants of business cycle interdependence in this region.

Although these studies contribute to a better understanding of the factors influencing business cycle interdependence, they have two important limitations. First, none of these studies account for model uncertainty, which is motivated by the lack of consensus in the theoretical and empirical business cycle literature regarding the main factors driving business cycle co-movement. Instead, these studies only rely on small pre-determined sets of potential determinants and assess their corresponding statistical significance, potentially incurring in a problem of omitted variables, which may yield bias estimates. As suggested in Sala-i-Martin et al. (2004), a natural way to think about model uncertainty is to admit that we do not know which model is "true" and, instead, attach probabilities to different models. Second, these studies use time-invariant measures of synchronization and therefore, are not able to identify the sources of potential changes in global business cycle interdependence. Moreover, if synchronization patterns and their potential determinants experience significant variation over time, a cross-sectional regression analysis may yield misleading insights about the underlying factors driving business cycle interdependence.

This paper analyzes the dynamics of global business cycle interdependence from different perspectives and assesses their main explanatory factors, accounting for the aforementioned issues. To study global synchronization from a disaggregated perspective, we rely on bilateral synchronizations and consider the time-varying index of business cycle interdependence recently proposed by Leiva-Leon (2016). This index endogenously identifies changes in the synchronization of economic cycles accounting for the non-linearity inherent to the alternation between expansions and recessions. To measure global synchronization from a unified perspective, we propose a nonlinear dynamic factor model that allows us to endogenously identify changes in the degree of comovement between a given country and the world business cycle, taking into account its expansionary and recessionary dynamics. This is achieved by allowing the factor to follow a global regime switching process and the loadings to be time-varying.

Our study proceeds in two steps. First, the dynamic interdependence between the main world economies is rigorously analyzed from intra-group, inter-group and global perspectives. Moreover, the proposed framework allows us to assess changes in the propagation pattern of business cycle shocks relying on network analysis. Second, after describing the time-varying patterns of global business cycle interdependence, we proceed to explain them with the traditional determinants in the literature. However, to account for model uncertain, we use a Bayesian model averaging (BMA) panel data approach. To the best of our knowledge, this is the first study that addresses model uncertainty in identifying the main drivers of business cycle interdependence over time.

Our main results can be summarized as follows. First, we document a significant and gradual increase in world business cycle synchronization. Specifically, global interdependence increased during the recent globalization period, since the early 2000s. ${ }^{1}$ Second, in addressing which countries have contributed the most to such increase, we perform a cluster analysis and find that countries can be grouped into four clusters, relatively stable over time: a Euro area cluster, an Anglo-Saxon cluster, an Asian Tigers cluster, and an emerging markets cluster. We find that the significant increase in global business cycle interdependence is mainly attributed to the emerging economies. Third, a network analysis of the transmission of business cycle shocks discloses that when countries become more synchronized with the rest of the world, they are more prone to recessionary phases than to expansionary phases. Fourth, the most robust determinants of business cycle co-movement are financial openness, bilateral trade, government expenditure, liquid liabilities and human capital. Fifth, the increase in global interdependence is mainly explained by decreasing differences in sectoral composition among countries.

In what follows, in Section 2 we study the changes of business cycle interdependence from inter-group, intra-group and global perspectives. In Section 3, we focus on assessing the factors driving the changes in global business cycle interdependence. Finally, Section 4 concludes the paper.

\section{Changes in business cycle interdependence}

This section provides a comprehensive analysis of the timevarying interdependence among the business cycles of the major world economies listed in Table $1 .^{2}$ Unlike previous related studies, we rely on measures of synchronization that allow for non-linear dynamics inherent in expansionary and recessionary phases. First, we construct global synchronization measures to assess potential changes in the overall interdependence among countries over time. Second, we classify countries based on their cyclical fluctuations and assess the main sources of changes in global interdependence. Third, we use methods for social network analysis to evaluate the relative influence of each country on the dynamics of world business cycles.

\subsection{Measuring global synchronization}

We rely on an extension of the approach proposed in Leiva-Leon (2015) to evaluate changes in the synchronization of business cycle phases. This methodology allows us to measure the synchronization in economic cycles between pairs of countries over time, taking into account the asymmetric nature of business cycles, i.e., nonlinear dynamics, and potential breaks in volatility, as documented in Doyle and Faust (2005). ${ }^{3}$ The methodology consists in assessing the

\footnotetext{
1 This result is consistent with Canova and Schlaepfer (2013) and Imbs (2006).

2 We consider this list of countries because we prefer to use quarterly GDP data, instead of annual, to obtain more precise inferences about expansions and recessions.

3 Using Monte Carlo experiments and an application for the economic activity of U.S. states, Leiva-Leon (2015) shows that this methodology is useful for tracking changes in synchronization. This framework is also applied to analyze the interdependence among U.S. industrial cycles in Camacho and Leiva-Leon (2014).
} 
Table 1

List of countries.

\begin{tabular}{llll}
\hline Country & ISO code & Country & ISO code \\
\hline Argentina & AR & Malaysia & MY \\
Australia & AU & Mexico & MX \\
Austria & AT & Netherlands & NL \\
Belgium & BE & New Zealand & NZ \\
Brazil & BR & Norway & NO \\
Bulgaria & BG & Philippines & PH \\
Canada & CA & Portugal & PT \\
Chile & CL & Romania & RO \\
China & CN & Singapore & SG \\
Denmark & DK & South Africa & ZA \\
Finland & FI & South Korea & KR \\
France & FR & Spain & ES \\
Germany & DE & Sweden & SE \\
Greece & GR & Switzerland & CH \\
Hong Kong & HK & Taiwan & TW \\
Iceland & IS & Thailand & TH \\
Indonesia & ID & Turkey & TR \\
Iraq & IQ & United Kingdom & GB \\
Ireland & IE & United States & US \\
Italy & IT & Venezuela & VE \\
Japan & JP & Africa & AA \\
Luxembourg & LU & & \\
\hline a & Of & &
\end{tabular}

a Because of the lack of data on real GDP for African countries, this series corresponds to an index of the overall economic activity of Africa.

time-varying dependency relationship between the latent variables governing bivariate Markov-switching specifications.

$\left[\begin{array}{l}y_{a, t} \\ y_{b, t}\end{array}\right]=\left[\begin{array}{l}\mu_{a, 0}+\mu_{a, 1} s_{a, t} \\ \mu_{b, 0}+\mu_{b, 1} s_{b, t}\end{array}\right]+\left[\begin{array}{c}\varepsilon_{a, t} \\ \varepsilon_{b, t}\end{array}\right]$,

where $y_{i, t}$ is the real GDP growth rate of country $i ; s_{i, t}$ is an unobservable state variable that indicates the phase of $y_{i, t}$, for $i=a, b$. The innovations $\varepsilon_{t}=\left[\varepsilon_{a, t}, \varepsilon_{b, t}\right]^{\prime}$ are distributed as $\varepsilon_{t} \sim N\left(\mathbf{0}, \Omega_{t}\right)$, where

$\Omega_{t}=\Omega_{0}\left(1-d_{t}\right)+\Omega_{1} d_{t}$

and $d_{t}$ is an unobserved state variable that indicates the regimes of volatility.

The state variables $s_{a, t}$ and $s_{b, t}$ evolve according to first-order Markov chains with transition probabilities:

$p\left(s_{k, t}=j_{k} \mid s_{k, t-1}=i_{k}\right)=p_{i j}^{k}$, for $i_{k}, j_{k}=0,1$ and $k=a, b$.

The expected growth of country $i$ during a recessionary phase, i.e., when $s_{i, t}=0$, is given by $E\left(y_{i, t} \mid s_{i, t}=0\right)=\mu_{i, 0}$, while its growth in expansionary phase, i.e., when $s_{i, t}=1$, is $E\left(y_{i, t} \mid s_{i, t}=1\right)=\mu_{i, 0}+\mu_{i, 1}$, for $i=a, b$. The state variable $d_{t}$ evolves according to a first-order Markov chain, independent from the state variables $s_{a, t}$ and $s_{b, t}$, and with transition probabilities:

$p\left(d_{t}=1 \mid d_{t-1}=1\right)=p^{d}$

$p\left(d_{t}=0 \mid d_{t-1}=0\right)=1$.

In order to account for a potential structural break in volatility, we follow Barnett et al. (2016) and truncate one of the transition probabilities to model an absorbing state. Accordingly, the covariance matrix of the innovations during a low volatility regime is given by $E\left(\varepsilon_{t} \varepsilon_{t}^{\prime} \mid d_{t}=0\right)=\Omega_{0}$, while during a high volatility regime, the covariance matrix is defined as $E\left(\varepsilon_{t} \varepsilon_{t}^{\prime} \mid d_{t}=1\right)=\Omega_{1}{ }^{4}$

The primary aim of the framework is to obtain the synchronization between the state variables $s_{a, t}$ and $s_{b, t}$ in order to assess whether countries $a$ and $b$ share the same business cycle phase at time $t$ :

$\operatorname{sync}\left(s_{a, t}, s_{b, t}\right)=p\left(s_{a, t}=s_{b, t}\right)$, for $t=1, \ldots, T$.

Although the relationship between $s_{a, t}$ and $s_{b, t}$ is unknown, we can model the two extreme cases, as in Harding and Pagan (1999), and express the joint probability of the state variables as follows:

i) If $s_{a, t}$ and $s_{b, t}$ are fully independent, then

$$
p\left(s_{a, t}=j_{a}, s_{b, t}=j_{b}, d_{t}=l\right)=p\left(s_{a, t}=j_{a}\right) p\left(s_{b, t}=j_{b}\right) p\left(d_{t}=l\right) .
$$

ii) If $s_{a, t}$ and $s_{b, t}$ are totally dependent, then $s_{a, t}=s_{b, t}=\varsigma_{a b, t}$; hence,

$$
p\left(s_{a, t}=j_{a}, s_{b, t}=j_{b}, d_{t}=l\right)=p\left(\varsigma_{a b, t}=j_{a b}\right) p\left(d_{t}=l\right) .
$$

To infer $p\left(s_{a, t}=j_{a}, s_{b, t}=j_{b}, d_{t}=l\right)$, Leiva-Leon (2015) enlarges the setting by introducing an additional state variable, $v_{a b, t}$, which facilitates the assessment of the dependency relationship between $s_{a, t}$ and $s_{b, t}$. This state variable, $v_{a b, t}$, is defined as:

$v_{a b, t}=\left\{\begin{array}{l}0 \text { If } s_{a, t} \text { and } s_{b, t} \text { are fully independent } \\ 1 \text { If } s_{a, t} \text { and } s_{b, t} \text { are completely dependent }\end{array}\right.$,

where $v_{a b, t}$ follows a Markov process with transition probabilities:

$p\left(v_{a b, t}=j_{v} \mid v_{a b, t-1}=i_{v}\right)=q_{i j}^{a b}$, for $i_{v}, j_{v}=0,1$.

By relying on $p\left(s_{a, t}=j_{a}, s_{b, t}=j_{b}, d_{t}=l \mid v_{a b, t}=j_{v}\right)$, that is, the joint probability of $s_{a, t}, s_{b, t}$, and $d_{t}$ conditional on $v_{t}$, inferences regarding the bivariate dynamics of the model in Eq. (1) can be expressed as a weighted average between the two extreme cases:

$p\left(s_{a, t}=j_{a}, s_{b, t}=j_{b}, d_{t}=l\right)=p\left(v_{a b, t}=1\right) p\left(s_{a b, t}=j_{a b}\right) p\left(d_{t}=l\right)$
$+\left(1-p\left(v_{a b, t}=1\right)\right) p\left(s_{a, t}=j_{a}\right) p\left(s_{b, t}=j_{b}\right) p\left(d_{t}=l\right)$,

where the weights are endogenously determined by

$p\left(v_{a b, t}=1\right)=\delta_{t}^{a, b}$

Notice that if $\delta_{t}^{a b}$ is close to one, then $s_{a, t}$ and $s_{b, t}$ are sharing similar dynamics; by contrast, $\delta_{t}^{a b}$ is close to zero, then $s_{a, t}$ and $s_{b, t}$ are following independent patterns at time $t$. Therefore, $\delta_{t}^{a b}$ provides a measure of the degree of synchronicity in the business cycle phases between countries $a$ and $b$ for every period of time. The parameters are estimated using Bayesian methods, Gibbs sampling, see Kim and Nelson (1999). The filtering algorithm that is used to obtain the inferences relies on an extension of the Hamilton's (1994) filter. For a detailed description of the filtering algorithm, see Appendix A.

To illustrate how the model's output should be interpreted, we present two cases. First, we analyze the case of Canada and Mexico,

\footnotetext{
4 The probability that $d_{t}$ will switch from state 1 (high volatility regime), at an unknown change point $\tau$, to state 0 (low volatility regime), at time $\tau+1$, is greater than zero. However, once the economy switches to state 0 , it will stay at this state permanently.
} 

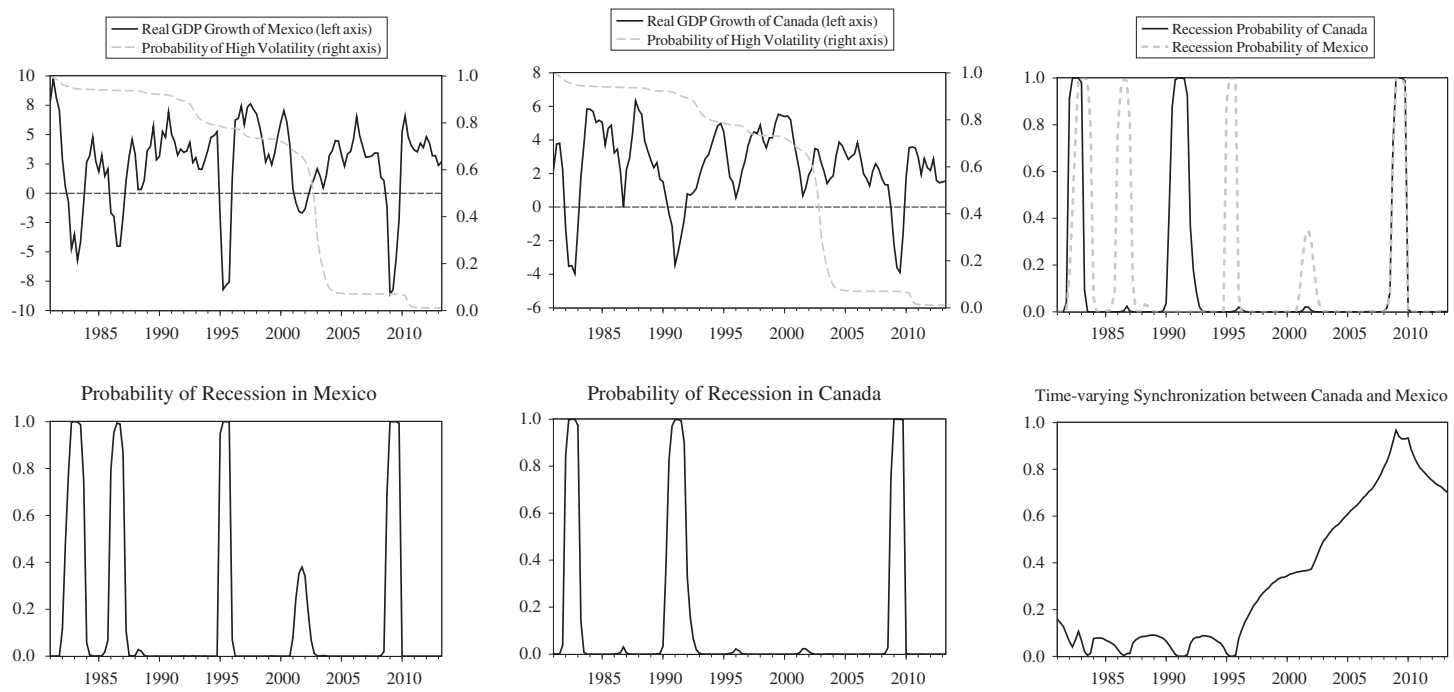

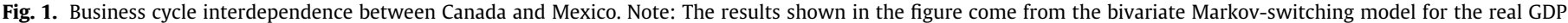
growth of Mexico and Canada. The sample period is 1981:Q1-2013:Q2.

shown in Fig. 1. The input of the model consists in the real GDP growth of both countries, $y_{C A, t}$ and $y_{M X, t}$, while the model's output consists in the recession probabilities for Canada and Mexico and the time-varying synchronization of their cycles, $\delta_{t}^{C A, M X}$, which has significantly increased during the recent globalization era, i.e., from 1995 onward. Before 1995, both economies experienced expansions and recessions at different points of time. However, after 1995, the probability of recession was low in both countries, and it simultaneously increased during the Great Recession of 2008-2009, as can be observed in the top right chart of the figure. This increase in may be highly influenced by the North American Free Trade Agreement, which came into force on January 1994. The model also provides inference about a change in the covariance matrix of the innovations driving real GDP growth of both countries, indicating that since the mid 2000s shocks hitting Canada and Mexico have experienced less volatile dynamics.

We also analyze the case of Australia and New Zealand, shown in Fig. 2. These economies experienced low levels of synchronization during the 1980s, but from the 1990s onward, their business cycle phases tend to experience similar dynamics. This is reflected in the increased synchronization plotted in the bottom right chart of Fig. 2. Such increase in synchronization may be associated with the total elimination of tariffs or quantitative restrictions in the Closer Economic Relations Trade Agreement between Australia and New Zealand, signed in July 1990. Based on the estimated probability of low volatility regime, the results also indicate that business cycle fluctuations in both countries have "moderated" since the mid 1990s.

Unlike the previous examples, there are also some pairs of countries that have experienced a relatively constant synchronization over time, e.g. United States and Canada, and the pairs of countries formed by the members of the Euro area in the G-7 (Germany, France and Italy). Also, we find an overall drop in the probability of high volatility regime during the last decades across countries, implying that growth seems to have stabilized. These results are consistent with the findings in Doyle and Faust (2005). ${ }^{5}$

The pairwise analysis is relevant if policy makers are focused on a specific pair of countries. However, since our interest is placed on "the big picture" of global synchronization's evolution, we

\footnotetext{
5 The results for all the possible pairs of countries listed in Table 1 are not reported to save space, since we estimate 903 different pairwise models $\left(C_{2}^{43}=903\right)$. However these results are available upon request.
}

summarize the results of the 903 pairwise models in a single index obtained by using all the synchronization measures, $\delta_{t}^{a, b}$ for $a \neq$ $b$. As these synchronization measures are estimated variables from Markov processes, we rely on simple non-parametric approaches to combine them without making any distributional assumptions. The simplest way to create a single index to measure global business cycle interdependence is by averaging the level of synchronization for all the 903 pairwise models:

$f_{t}^{a}=\frac{1}{L} \sum_{l=1}^{L} \delta_{t}^{l}$,

for $l=1, \ldots, L$, where $l$ denotes the $l$-th pairwise model, $n$ is the number of countries, $L=n(n-1) / 2$, and $f_{t}^{a}$ represents the average synchronization. For robustness, we also consider another measure, which consists on extracting the common variation from the synchronization measures by using principal component analysis:

$\delta_{t}^{l}=\lambda_{l} f_{t}^{c}+u_{l, t}$

for $l=1, \ldots, L$, where $\lambda_{l}$ are the factor loadings, $u_{l, t}$ has a zero mean and an unknown diagonal covariance matrix and $f_{t}^{c}$ is the first principal component, which accounts for most of the variation in the data and therefore represents common synchronization. ${ }^{6}$

The two indexes of global synchronization, plotted in Fig. 3, show similar patterns. Until the late 1990s, global business cycle synchronization was relatively low and stable; however, in the early 2000s, it started to continuously increase, reaching its maximum level at the end of 2008, i.e., in the middle of the last global recession, as dated by the IMF. These findings imply that world economic activity has become more synchronized during the last two decades, suggesting a change in the propagation of business cycle shocks among countries. It is important to notice that after the Great Recession, many European countries continued to experience recessionary phases, due to the European debt crisis, while most of the emerging markets

\footnotetext{
6 Given that principal component requires the data to be standardized prior to use, we rescale the extracted factor by using $\frac{f-f_{\text {MIN }}}{f_{\text {MAX }}-f_{\text {MIN }}}$, where $f_{\text {MIN }}$ is the factor with the minimum variance and $f_{M A X}$ is the factor with the largest variance, the first factor. This transformation makes the index belong to the unit interval to facilitate interpretation. This has no effect on any of the subsequent results obtained from the use of index.
} 

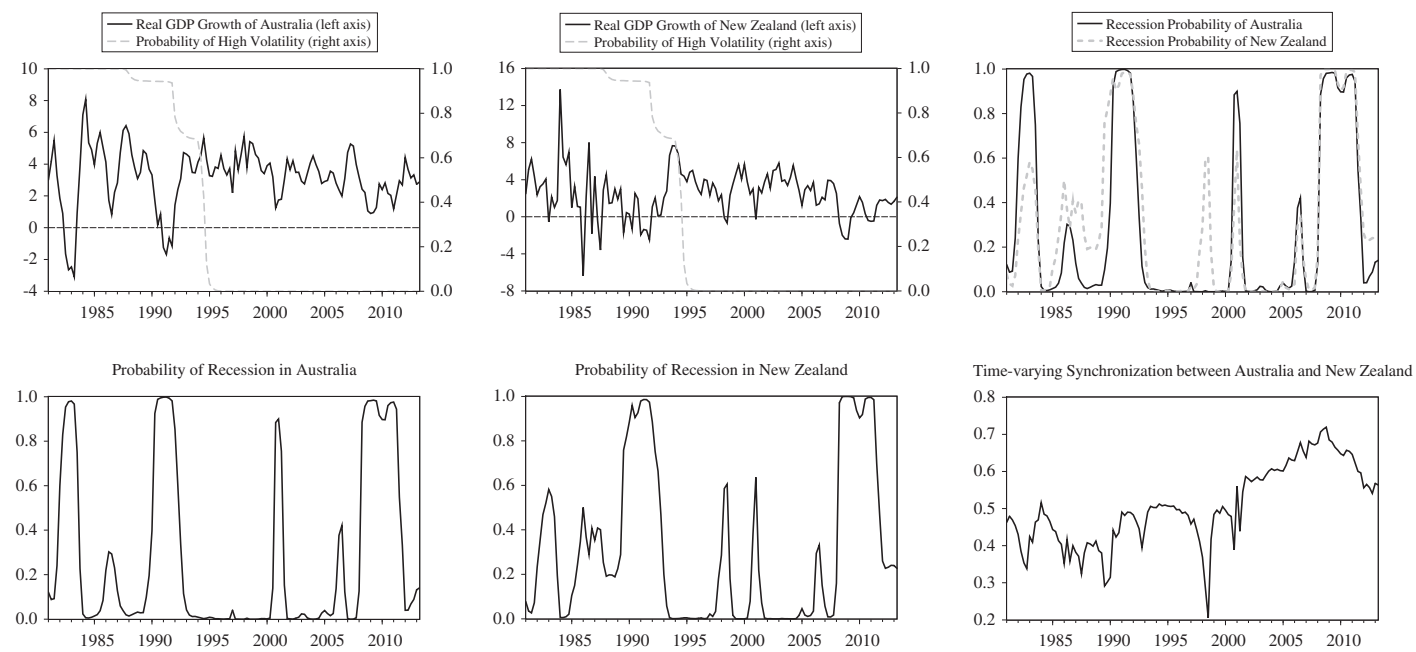

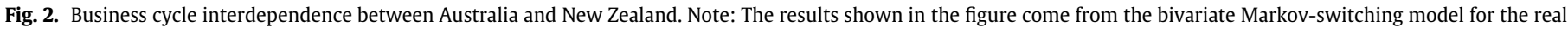
GDP growth of Australia and New Zealand. The sample period is 1981:Q1-2013:Q2.

engaged in expansionary phases. This heterogeneity is reflected in the decrease in global synchronization after the great crisis.

\subsection{Source of the increase in global interdependence}

The purpose of this section is to assess the main source of the increase in global synchronization from the country perspective. Specifically, we are interested in identifying the set of countries that have contributed the most to the significant gradual increment in global interdependence. For this purpose, first, we analyze whether there are groups of countries experiencing similar business cycle patterns. Second, we analyze the evolution of the interdependence between groups of countries and infer the main drivers of the increase in global interdependence. Third, we assess changes in the comovement between each country and the world economic activity. This analysis allows us to identify the set of country that have engaged in a higher synchronization with the rest of the world.

\subsubsection{Intra-group interdependence}

We use an agglomerative hierarchical cluster tree (Ward's linkage method) to identify groups of countries with similar dynamics in

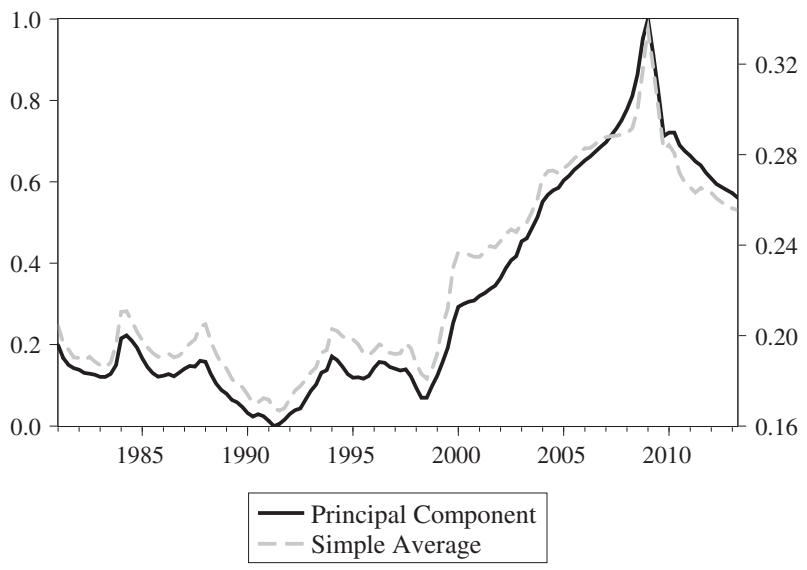

Fig. 3. Global time-varying synchronization. Note: The solid line (left axis) represents an index of global business cycle interdependence obtained by taking the first principal component between each of the pairwise synchronization measures across countries. The dashed line (right axis) represents an index of global business cycle interdependence obtained by averaging the pairwise synchronization measures across models. The sample period is 1981:Q1-2013:Q2. their business cycle phases. As the Ward's linkage method uses a distance measure to group countries into different clusters, we convert the synchronization measures, $\delta_{t}^{a, b}$, into de-synchronization measures as follows:

$\gamma_{t}^{a, b}=1-\delta_{t}^{a, b}$

where the de-synchronization index, $\gamma_{t}^{a, b}$, may be interpreted as the cyclical distance. A detailed description of the clustering approach is provided in Appendix B.

The cluster analysis is summarized in dendrograms. Using the transition probabilities in Eq. (7), we compute the ergodic measure, $\bar{\delta}^{a, b}$, which can be interpreted as the "average" synchronization between countries $a$ and $b$ for the entire sample period (19812013). Then, we obtain the ergodic distance, $\bar{\gamma}^{a b}$, and the correlation dissimilarity matrix of business cycle distances, $D=1-|\operatorname{corr}(\bar{\gamma})|$, to create a dendrogram that represents the average clustering configuration of countries, shown in the top chart of Fig. $4 .^{7}$ The height of each tree determines the different clusters, i.e., the height of the inverted $U$ represents the level of dissimilarity between two countries or clusters. It is possible that some of the observed clusters are caused by outliers or sampling error. We assess uncertainty in the group assignments using a multiscale bootstrap resampling to compute the approximately unbiased (AU) p-values. ${ }^{8}$ For clusters with $\mathrm{AU}$ p-value greater than 95 , we can reject the null hypothesis that "the cluster does not exist" at the $5 \%$ significance level.

We find that there are at least four groups of countries with similar patterns of business cycle synchronization. First, there is a cluster comprising France, Italy, Switzerland, Belgium, Netherlands, Austria, Germany, Ireland, Greece, Luxembourg, Portugal, and Spain. Since all these countries, except Switzerland, share the same currency, we define this group as the "Euro area cluster". The second group comprises Norway, Denmark, the U.S., Australia, Iraq, Iceland, Canada, Finland, New Zealand, Sweden, and the U.K. This cluster consists of mostly advanced Anglo-Saxon countries and some European countries; hence, we define this group as the "Anglo-Saxon

\footnotetext{
7 The ergodic probabilities are computed as $\bar{\delta}_{i}^{a, b}=\left(1-q_{00}^{a b}\right) /\left(2-q_{00}^{a b}-q_{11}^{a b}\right)$, where $q_{i j}^{a b}$ represents the estimated transition probabilities associated with the state variable, $v_{t}$, that measures synchronization.

8 See Efron et al. (1996) and Shimodaira (2002) for a detailed explanation of the multiscale bootstrap resampling. We use $1,000,000$ bootstraps to reduce sampling error in the AU p-values.
} 


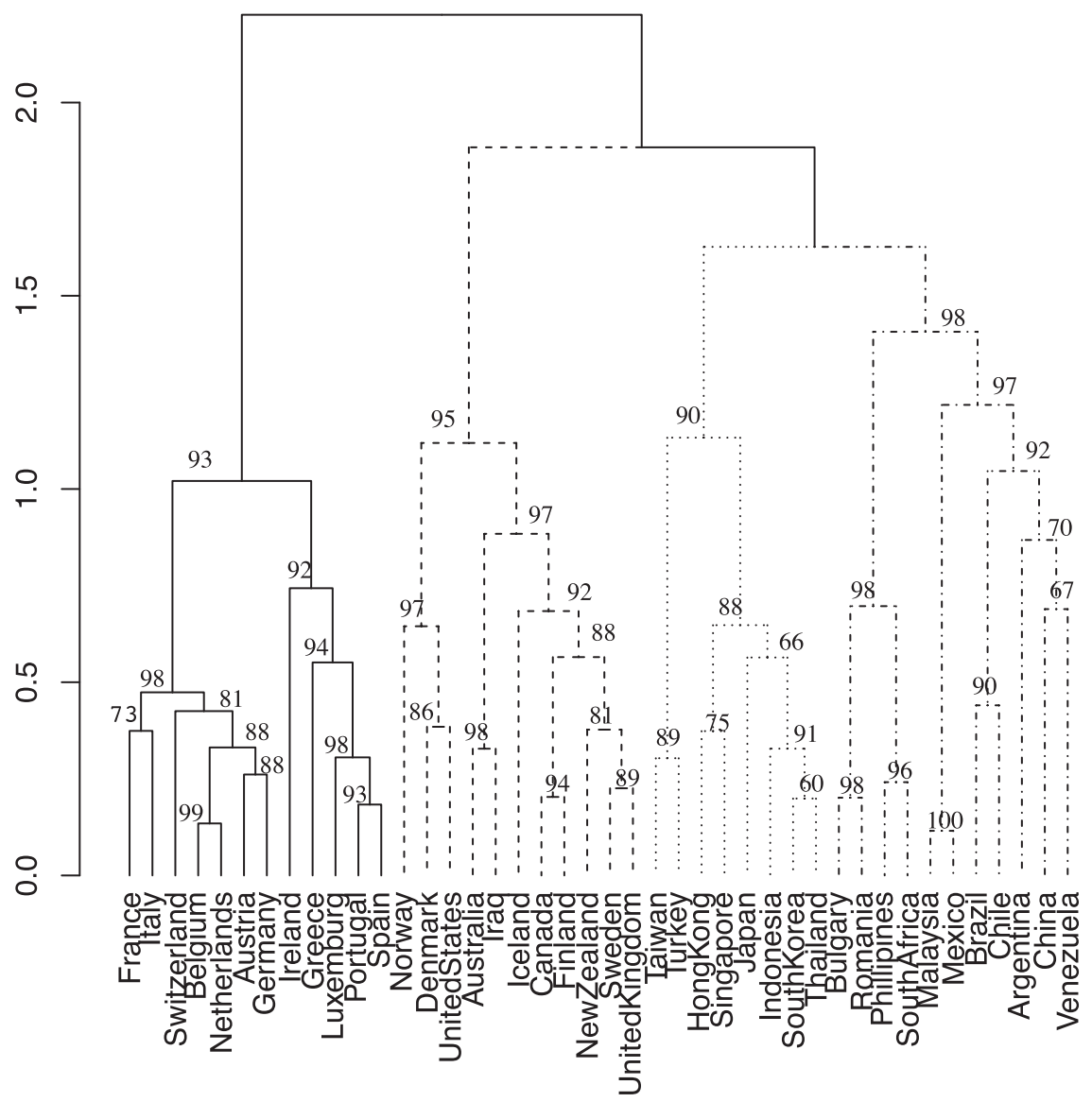

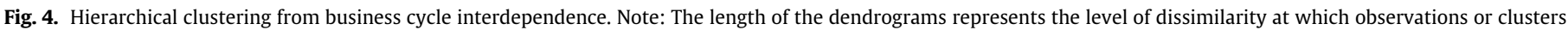
are merged. AU p-values greater than 90 indicate that $H_{0}$ : "cluster does not exist", can be rejected at the $10 \%$ significance level.

cluster". The third group comprises Taiwan, Turkey, Hong Kong, Singapore, Japan, Indonesia, South Korea, and Thailand. Given that most of these Asiatic nations have recently enjoyed a dramatic economic upswing, we call this group the "Asian Tigers cluster". The last cluster includes Bulgaria, Romania, Philippines, South Africa, Malaysia, Mexico, Brazil, Chile, Argentina, China, and Venezuela. These countries are considered by the IMF to be emerging economies, so we call this group the "emerging markets cluster". This clustering analysis provides a reasonable description of how countries share similar expansions and recessions and shows that geographic and cultural factors are important factors driving economic interdependence among countries within the Euro area, Asian Tigers, and Anglo-Saxon clusters. The existence of an emerging markets cluster also suggests that countries' level of economic development is an important factor explaining business cycle co-movement. These four clusters of countries are statistically significant at the $10 \%$ level. However, some sub-clusters such as Denmark-United States, Argentina-China-Venezuela, New Zealand-Sweden-United Kingdom and the Asian sub-clusters (with the exception of the Indonesia-South Korea-Thailand sub-cluster) are not statistically significant, even at the $10 \%$ level. ${ }^{9}$

\footnotetext{
9 We also examine if the groups of countries change over time by dividing the sample in three periods and performing the clustering analysis in each subsample. The results, not presented for the sake of brevity, suggest that the clusters are relatively stable over time.
}

\subsubsection{Inter-group interdependence}

Once groups experiencing similar cyclical fluctuations have been identified, our next goal is to analyze how the interdependence among these groups has evolved over time in order to examine where the increase in global business cycle interdependence is coming from.

For this purpose, we rely on multidimensional scaling maps. These techniques consist on projecting the business cycle distances among the $N$ countries in a map in such a way that the Euclidean distances among the countries plotted in the plane approximate the business cycle dissimilarities. In the resulting map, countries that exhibit large business cycle dissimilarities have representations in the plane that are far away from each other. Moreover, we use the time-varying business cycle distances, $\gamma_{t}^{a, b}$, to create a sequence of maps, one for each $t$, that can help us to analyze the dynamic evolution of the interdependence of countries and groups of countries and to disentangle the main source of the increase in global synchronization. A detailed description of dynamic multidimensional scaling (DMS) analysis is provided in Appendix C.

Fig. 5 plots the maps for selected periods during global recessions, as dated by the IMF. For illustration purposes only, we draw a link between countries $a$ and $b$ if their business cycle synchronization during period $t$ is larger than 0.5 , i.e., $\delta_{t}^{a, b}>0.5$. The distance between the countries in the graph approximates their business cycle synchronization, so the closer two countries in each graph are, the more synchronized they are. Notice that the depiction in the figure coincides fairly well with the clustering patterns obtained in Section 2.2.1. 


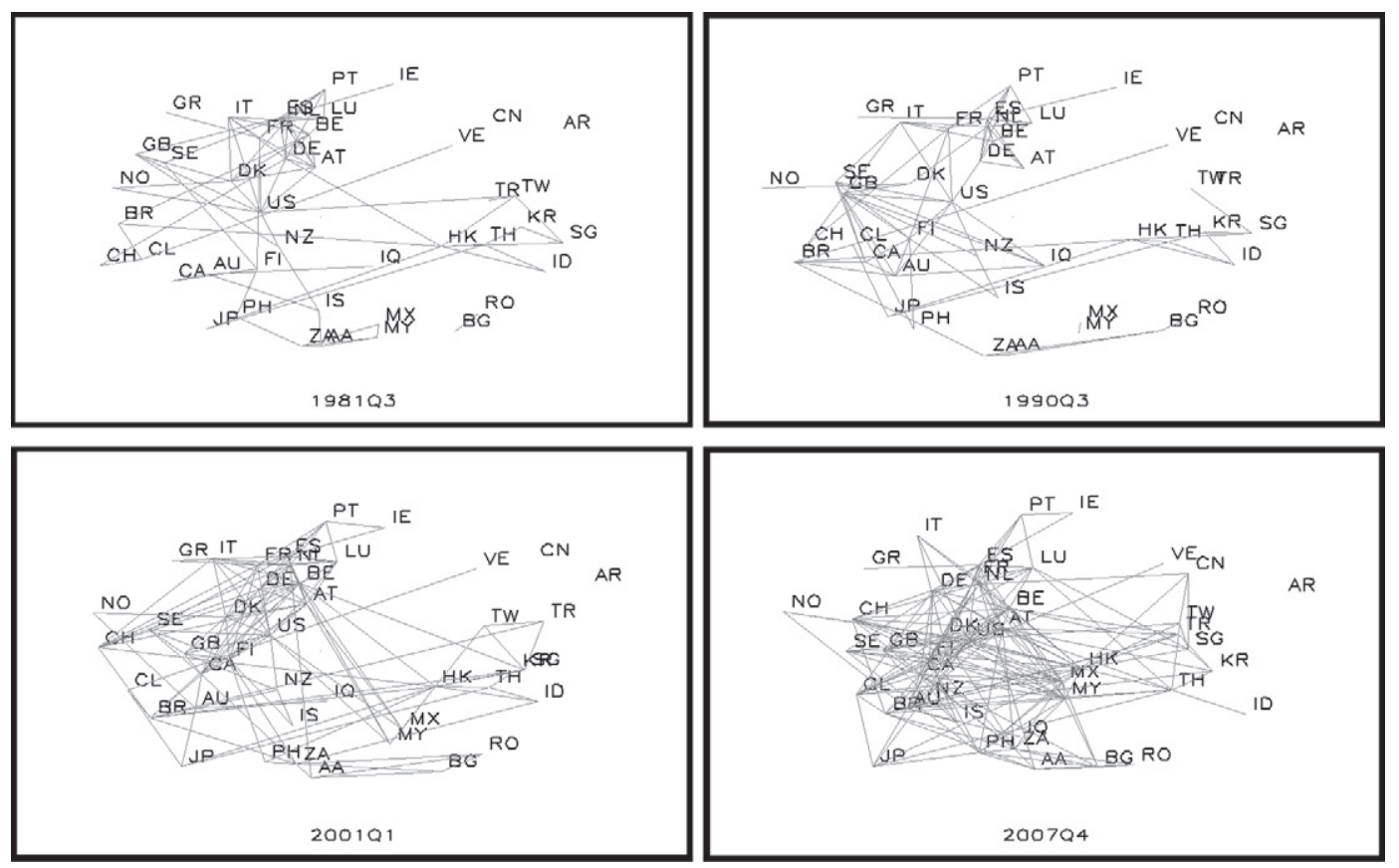

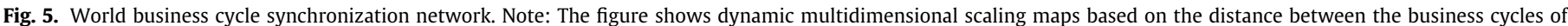

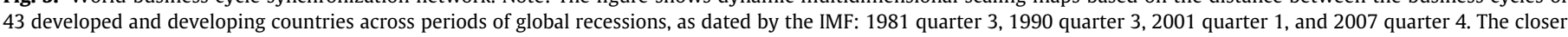

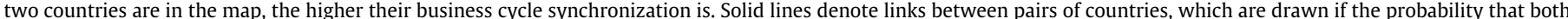

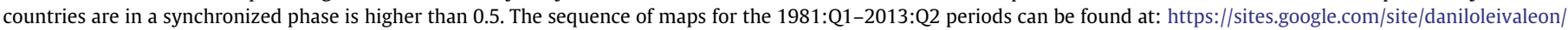
global-business-cycles.

During early 1980s global recession (top left chart of Fig. 5), the Euro area cluster shows the highest within-group interdependence, followed by the Asian Tigers cluster and Anglo-Saxon cluster that experience a lower degree of within-group interdependence. For the early 1990s global recession (top right chart), the Euro area and Asian Tigers clusters maintain their degree of interdependence, but countries in the Anglo-Saxon cluster start to become more connected. However, most of the emerging markets remain isolated, as is the case of Mexico, Malaysia, and Turkey, among others. In the early 2000s global recession (bottom left chart), the picture changes considerably, showing a more connected map. The Euro area, Asian Tigers and Anglo-Saxon clusters continue to be highly related, but most of the countries in the emerging markets cluster, which is the largest cluster, become more interdependent with the rest of the world. Notice that this period corresponds to the significant and gradual increase in global synchronization, as discussed in Section 2.1. Thus, this increase in global business cycle interdependence can be mainly attributed to emerging economies. During the Great Recession (bottom right chart), the map experiences the highest connectivity, which is consistent with the propagation of contractionary shocks through most of the economies during that period. For the sake of brevity, we do not present the charts for all the world business cycle maps for every quarter from 1981 to $2013 .{ }^{10}$

\subsubsection{Interdependence with global factor}

By relying on bilateral synchronization measures, the previous sections show that the business cycles of emerging economies have become more synchronized with the economic cycles of the other

\footnotetext{
10 However, the complete sequence is available at the authors' website. We use all the charts of the different maps periods to create a video that shows the evolution of the world business cycle interdependence from 1981 to 2013. The video can be found at: https://sites.google.com/site/daniloleivaleon/global-business-cycles.
}

countries in the world, contributing significantly to the increase in global interdependence starting in the early 2000s. Although the previous analysis in this paper is based on the results from independent pairwise models, we attempt to mitigate this caveat by adopting a more integrated perspective. Specifically, we follow the line of Kose et al. (2012) and rely on dynamic factor models to identify changes in the degree of comovement between a given country and the world business cycle.

To capture changes in comovement without having to rely on specific partitions of the sample, as in Kose et al. (2012), we follow a closer approach to Del Negro and Otrok (2008) that allows for time-varying factor loadings. In particular, we propose a framework that allows us to assess changes in comovement, but also accounting for the nonlinear nature of the world business cycle. The proposed model can be described as follows:

$y_{\kappa, t}=\gamma_{\kappa, t} f_{t}+\epsilon_{\kappa, t}$, for $\quad \kappa=1,2, \ldots, N$

$f_{t}=\tilde{\mu}_{0}+\tilde{\mu}_{1} s_{t}^{*}+e_{t}$

where $y_{\kappa, t}$ is the real GDP growth of country $\kappa, f_{t}$ is a common factor that depends on the state of the world economy, measured by the latent variable $s_{t}^{*}$. The expected global growth during a recessionary phase, i.e. when $s_{t}^{*}=0$, is given by $E\left(f_{t} \mid s_{t}^{*}=0\right)=\tilde{\mu}_{0}$, while its growth in an expansionary phase, i.e. when $s_{t}^{*}=1$, is given by $E\left(f_{t} \mid s_{t}^{*}=1\right)=\tilde{\mu}_{0}+\tilde{\mu}_{1}$. The vector $\epsilon_{t}=\left[\epsilon_{1, t}, \epsilon_{2, t}, \ldots, \epsilon_{N, t}\right]^{\prime}$ collects the idiosyncratic terms, where $\epsilon_{t} \sim N(0, \Upsilon), \Upsilon$ is diagonal, and $e_{t} \sim N(0,1)$, for identification purposes.

The latent variable $s_{t}^{*}$ evolves according to a first-order Markov chain with transition probabilities

$p\left(s_{t}^{*}=j^{*} \mid s_{t-1}^{*}=i^{*}\right)=p_{i j}^{*}, \quad$ for $i^{*}, j^{*}=0,1$. 
The factor loadings, $\gamma_{\kappa, t}$, measure the contemporaneous relationship between country-specific real activity developments, $y_{\kappa, t}$, and the global business cycle, $f_{t}$. Therefore, to infer significant changes over time in international business cycle comovement, we follow the line of Del Negro and Otrok (2008), Koop and Korobilis (2014), among others, and allow the factor loadings to evolve according to a random walk, as follows:

$\gamma_{\kappa, t}=\gamma_{\kappa, t-1}+\eta_{\kappa, t}$

where $\eta_{\kappa, t} \sim N\left(0, \sigma_{\eta, \kappa}\right)$, for $\kappa=1,2, \ldots, N$. We estimate the model by relying on the multi-move Gibbs sampler. Further details about the Bayesian estimation method are reported in Appendix D.

The top chart of Fig. 6 plots the estimated global factor, $f_{t}$, along with the IMF world real GDP growth, showing a close relationship between them. The bottom chart of Fig. 6 plots the probability of global recession. The figure indicates a probability of global recession higher than 0.8 during the following periods: 1981:Q11983:Q1, 1992:Q2-1993:Q3, 2001:Q3-2003:Q3, 2008:Q3-2009:Q4. These periods fairly coincide with global recessions as dated by the IMF, indicating that the proposed global factor is a good indicator of the world economy business cycle. Notice, however, that the last part of the sample (2011:Q4-2013:Q2) is also associated with a high probability of recession. This could be mainly attributed to the recessionary phases that Euro area countries have experienced since 2011 as a result of the European debt crisis.

The main purpose of this section is to identify potential changes in comovement between each country and the world business cycle, therefore we now focus on analyzing the evolution over time of the factor loadings. Fig. 7 plots the loadings for countries in the AngloSaxon and Euro area clusters. The figure shows that the comovement of countries in the Anglo-Saxon cluster with the world business cycle, measured by the corresponding factor loadings, has remained relatively stable. For the case of the Euro area countries there are mix signals, while Germany and Belgium have experienced significant increases in the degree of comovement, France has remained relatively stable, and the comovement of Italy has decreased. Fig. 8 plots the loadings for countries in the Asian Tigers and emerging markets clusters. The figure shows that the loadings associated to the Asian Tiger economies have in general experienced slightly decreasing dynamics. However, the scenario is different for countries in the emerging markets cluster, since all emerging economies show a gradual but significantly increasing relationship with the global factor.

Overall, the results show that there is a considerable variation over time in the degree of comovement. Significant increments in comovement can be seen for some countries in the Anglo-Saxon cluster, such as Sweden and Finland, and for some Euro area countries, such as Austria and Ireland. Asian Tiger countries, instead seem to have become less synchronized with the global factor. However, most of the emerging markets have experienced significant increases in comovement with the world business cycle. These results corroborate that emerging economies have played a fundamental role in explaining the increase in global business cycle interdependence during the last decades.

Unlike Kose et al. (2012), who find business cycle convergence within groups of industrial and emerging market economies but divergence between both groups, we obtain that the main source of the significant increase in global business cycle synchronization is the emerging market economies. The countries in this cluster experienced independent cyclical patterns until the late 1990s. However, since the early 2000s, they became more synchronized with each other and with the rest of clusters. The main difference between the analysis in Kose et al. (2012) and ours, besides the assumptions about the dynamics of the models, relies on the sample period considered,

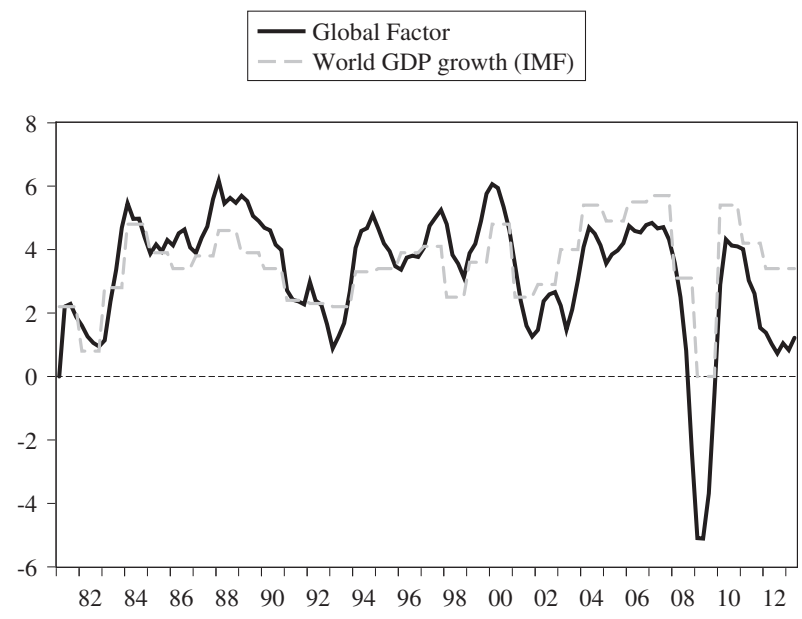

Probability of Global Recession

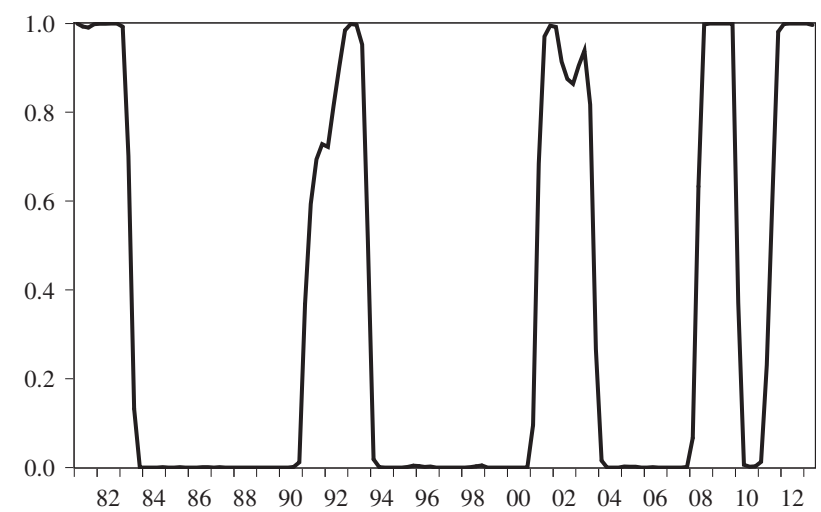

Fig. 6. Global business cycle factor. Note: Top chart plots the global factor (solid line) along with the world GDP growth computed by the IMF (dashed line). Bottom chart plots the probability of a global recession based on the global factor. The sample period is 1981:Q1-2013:Q2.

since Kose et al. (2012) focus on studying changes in comovement before and after the Great Moderation, while our study focuses exclusively on identifying changes in business cycle interdependence during the post-Great Moderation period. ${ }^{11}$

\subsection{Transmission of business cycle shocks}

World economic interlinkages can be viewed as a complex system comprising a set of elements (countries), in which any pair of elements is subject to some degree of interdependence that may change over time. We model world economic interlinkages as a network, $g_{t}$, by using the synchronization measures obtained in Section 2.1, where each country represents a node and where the probability that

\footnotetext{
11 In contrast to Kose et al. (2012) that rely on a linear framework to asses synchronization, we consider a nonlinear dynamic factor model. The analysis of Kose et al. (2012) focuses on the sample period 1960-2008, since they rely on annual data. Instead, we rely on quarterly data to be able to capture expansions and recessions more precisely, at the cost of a shortening of our sample, 1982-2013. Therefore, we focus on the post-Great Moderation period and also include the Great Recession, while Kose et al. (2012) include the pre-Great Moderation period but exclude the Great Recession.
} 
(a) Anglo saxon cluster
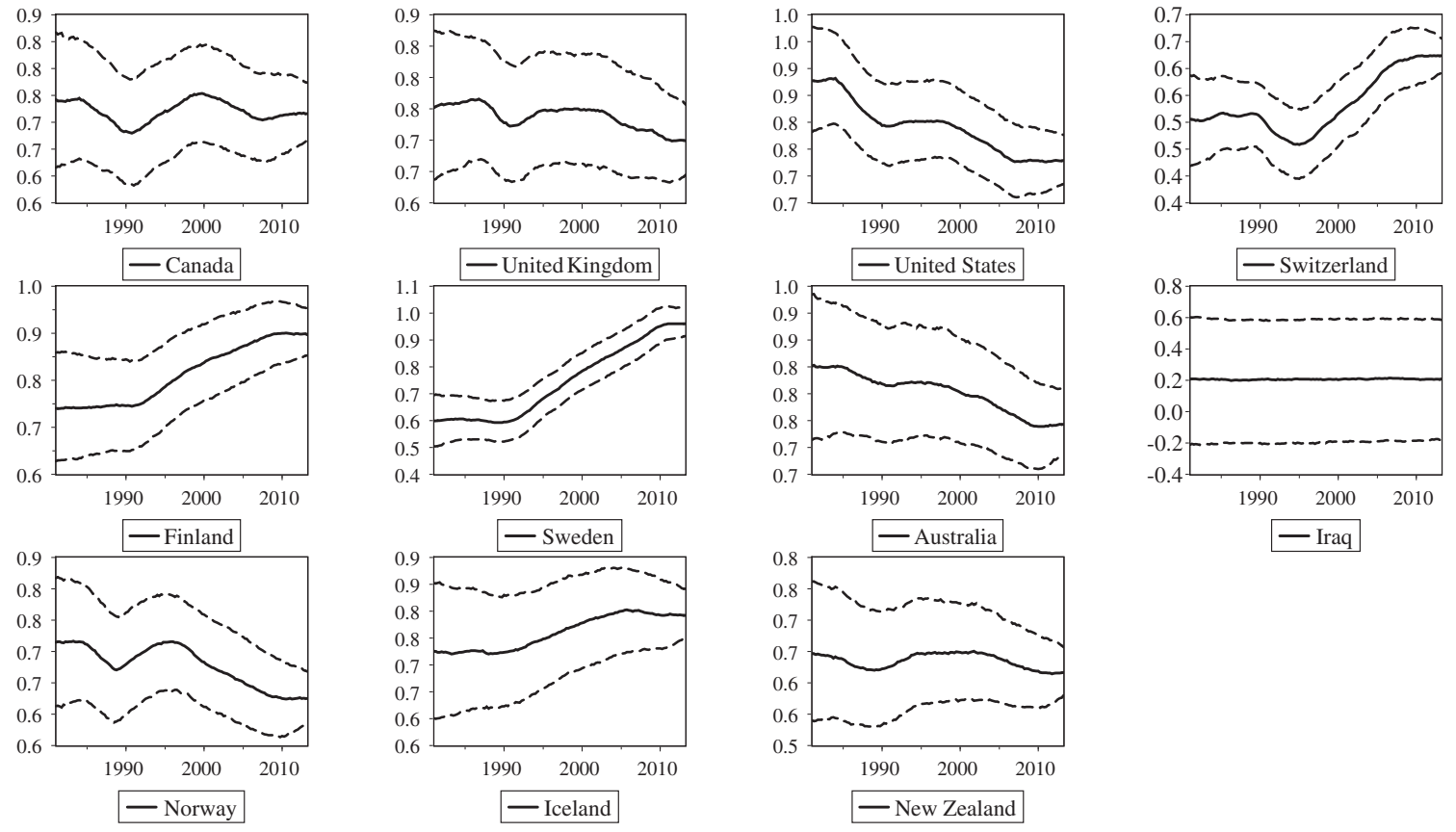

(b) Euro area cluster
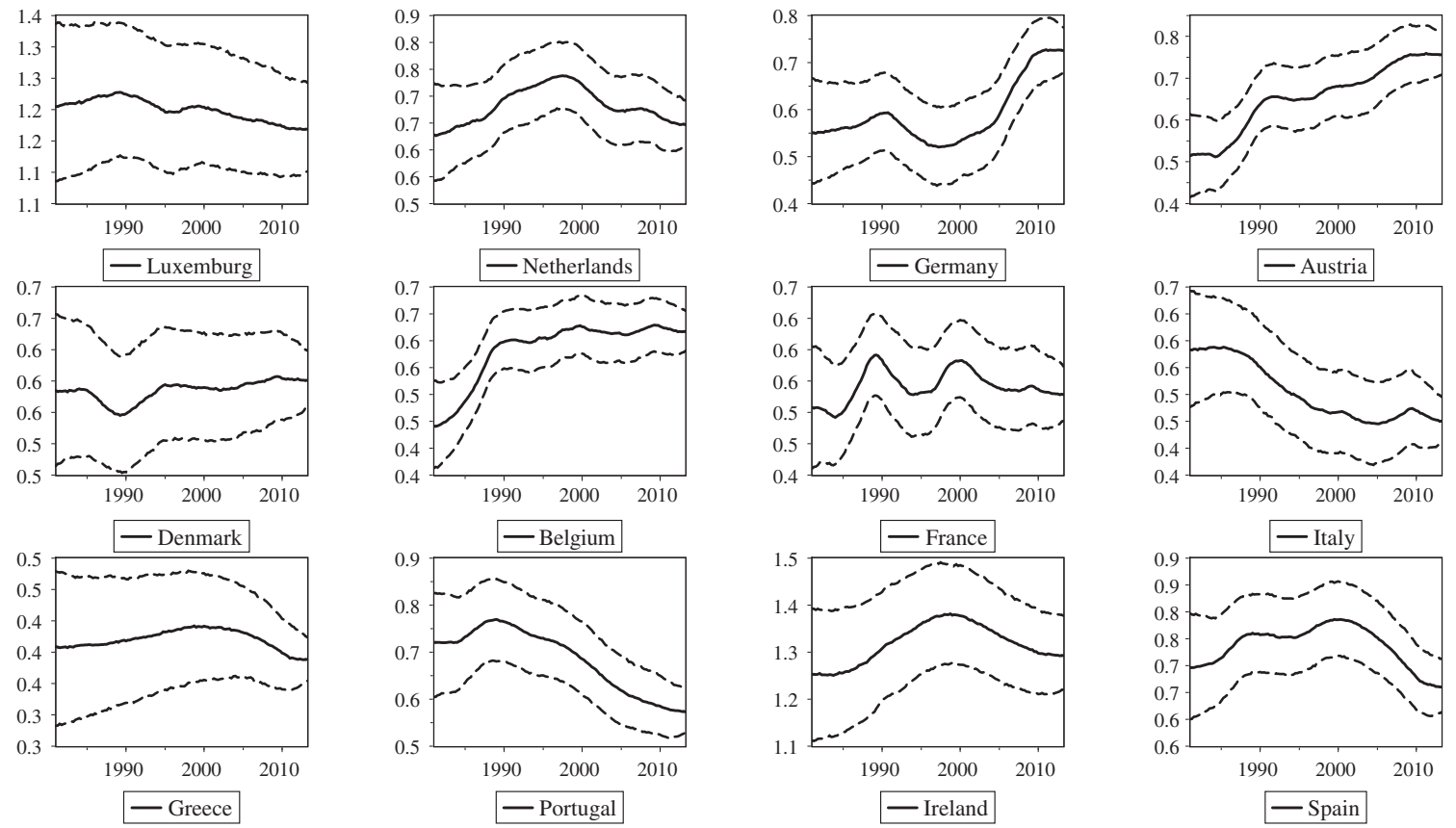

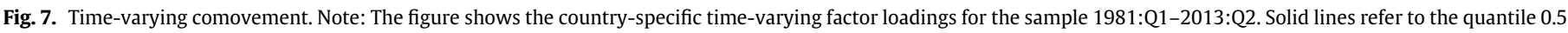
of the posterior distribution estimates, while dashed lines refer to the 0.1 and 0.9 quantiles.

two nodes, $a$ and $b$, are linked at time $t$ is given by $\delta_{t}^{a, b}$. Thus, the more synchronized the countries are, the higher the degree of connectivity in the network will be. The motivation for adopting this approach is to provide a better understanding of the propagation pattern of business cycle shocks across the major world economies.
We use methods developed for social network analysis to evaluate how a particular economy is simultaneously synchronized with the rest of the economies in the world and to quantify the relative importance of each country in the propagation of shocks to other economies. In particular, we consider the betweenness centrality, $B_{i, t}$, since this measure can be interpreted as the ability of country $i$ to act 
(a) Asian tigers cluster
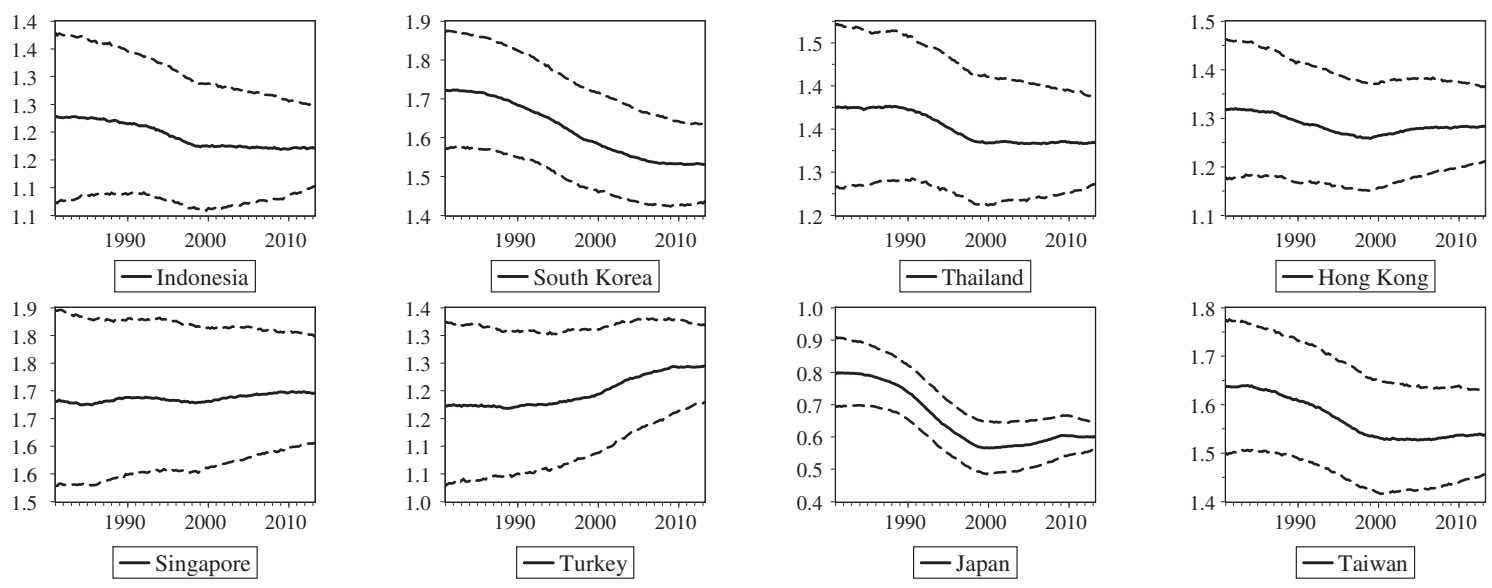

(b) Emerging Markets cluster
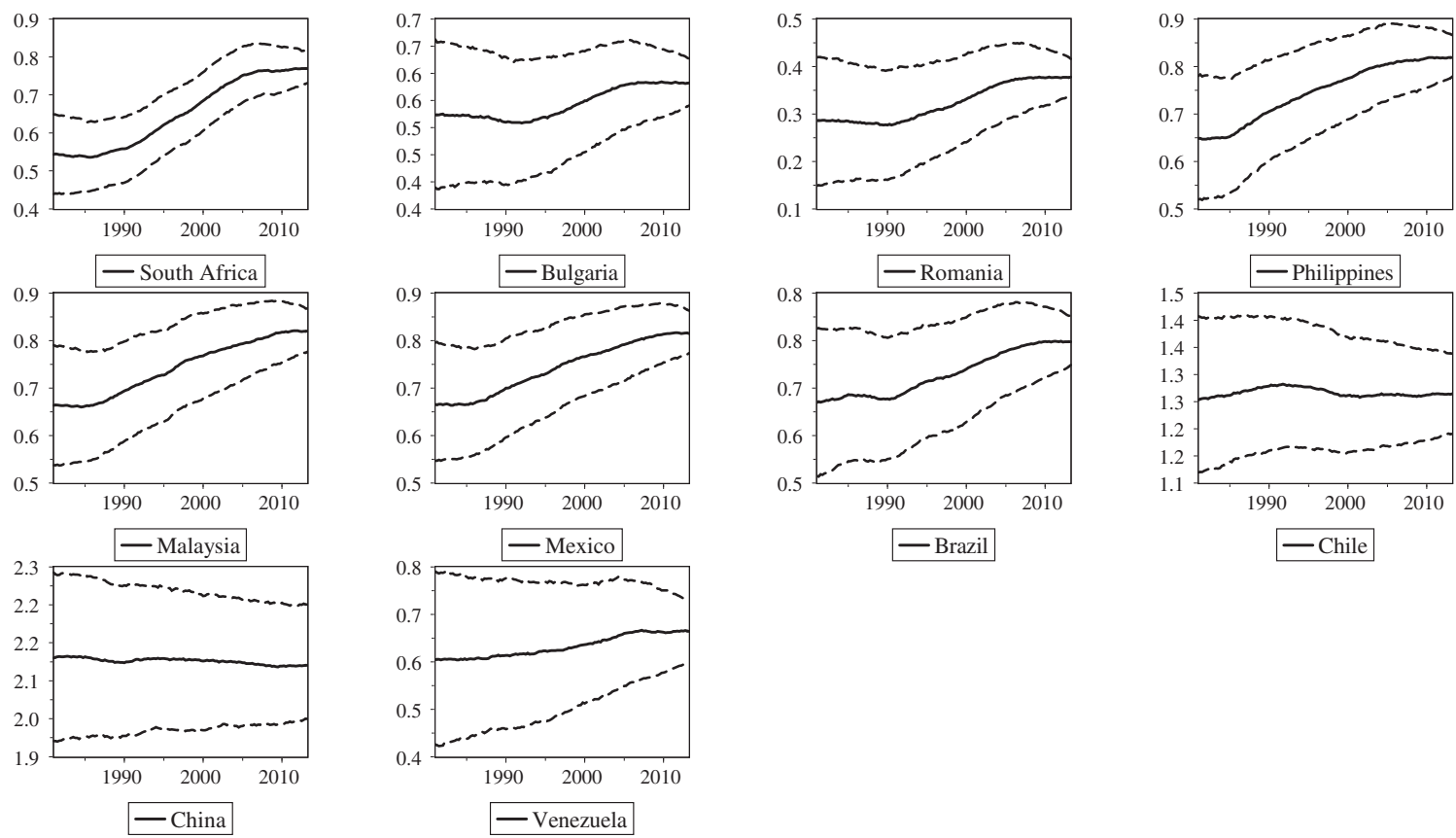

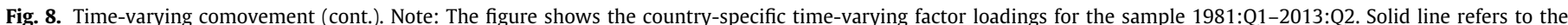
quantile 0.5 of the posterior distribution estimates, while dashed lines refer to the 0.1 and 0.9 quantiles.

as a channel in the transmission of business cycle shocks between other countries in the network $g_{t}$ during period $t .^{12}$ The betweenness centrality is calculated as

$B_{i, t}=\sum_{j \neq k: j, k \neq i} \frac{\tau_{j, k}^{i}\left(g_{t}\right)}{\tau_{j, k}\left(g_{t}\right)}$,

\footnotetext{
12 According to Forni and Gambetti (2010) supply shocks explain most of the GDP volatility. Thus, the betweenness centrality might capture the relative importance of
} each country in the propagation of supply shocks to other economies. where $\tau_{j, k}^{i}\left(g_{t}\right)$ is the number of shortest paths between $j$ and $k$ in $g_{t}$ that pass through country $i$ and $\tau_{j, k}\left(g_{t}\right)$ is the total number of shortest paths between $j$ and $k$ in $g_{t} .{ }^{13}$

To assess the evolution of the countries' centrality over the business cycle, we define recessionary phases for each economy as a period where the Markov-switching probability of recession is higher than 0.7. Both time-varying betweenness centrality and recessionary episodes for most of the countries are plotted in Fig. 9,

13 A shortest path between two countries $a$ and $b$ in the weighted global business cycle network, $g_{t}$, is simply a directed path from $a$ to $b$ with the property that no other such path has a lower weight. 

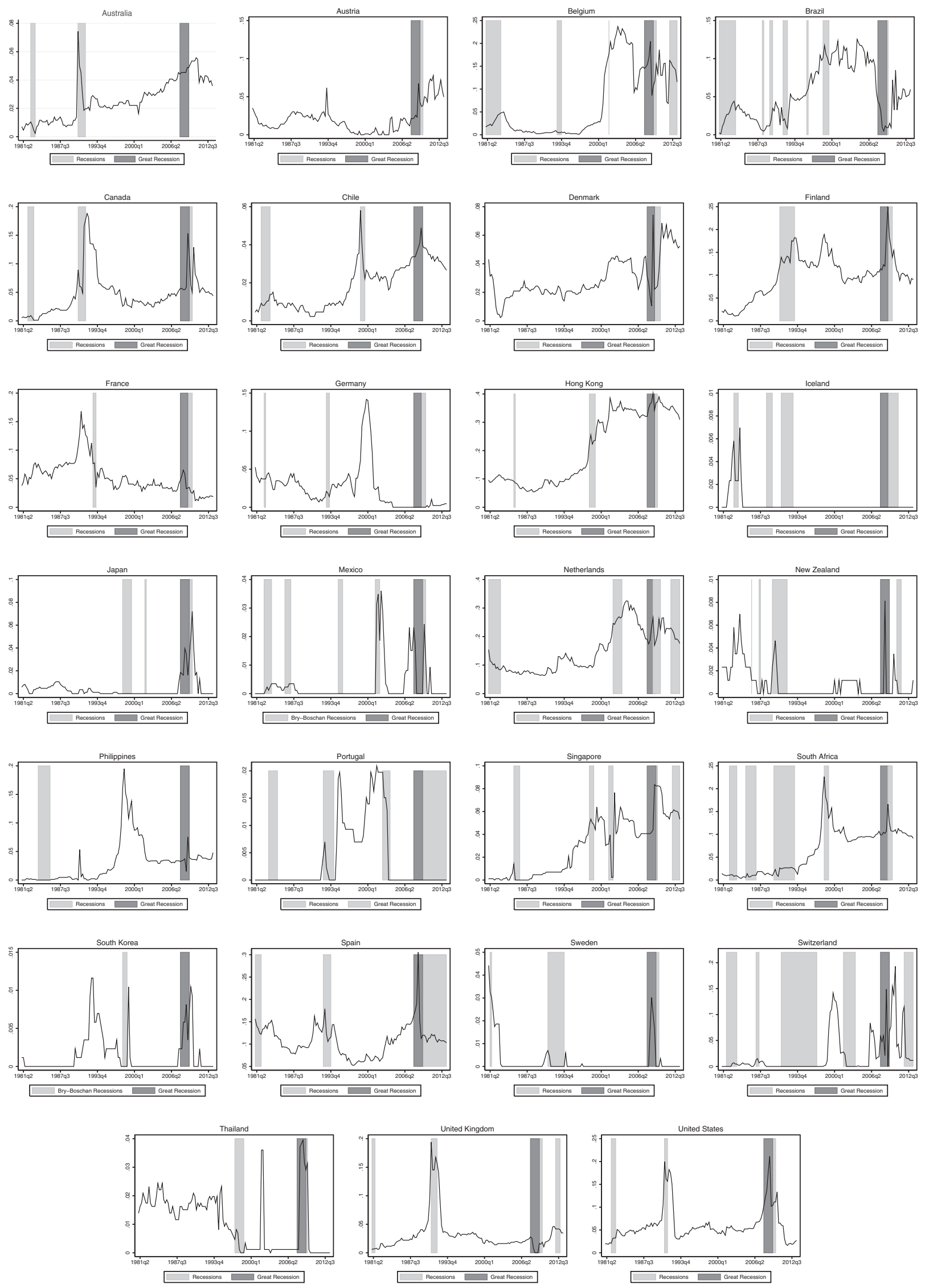

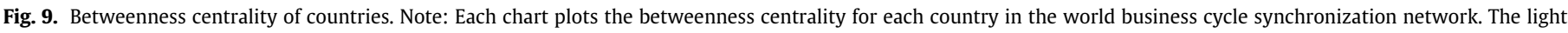

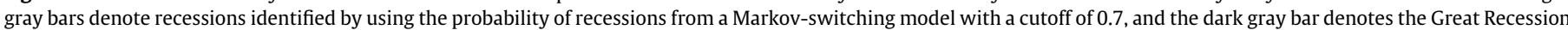
of 2007-2009. 


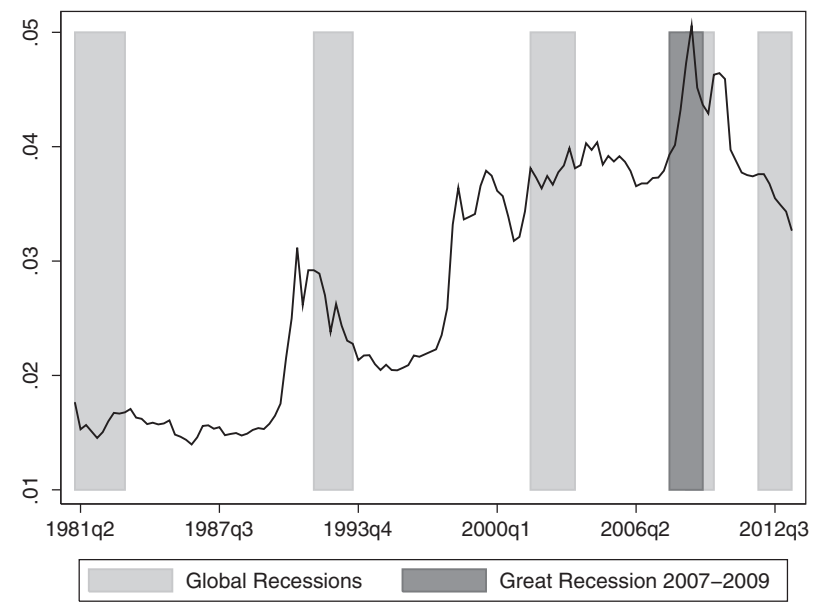

Fig. 10. Average betweenness centrality. Note: The figure plots the average betweenness centrality across countries. The light gray bars denote recessions identified by using the probability of recessions from a Markov-switching model with a cutoff of 0.7 , and the dark gray bar denotes the Great Recession of 2007-2009.

showing a close relation between them. For the rest of countries, the centrality was equal to zero for the entire sample period, and therefore not reported.

In general, a country's centrality tends to increase during periods of national recessions, returning to lower levels during economic expansions. This is also the case for the Great Recession (20072009) where most of the countries became more central. This finding suggests that when countries become more globally synchronized, they are more prone to contractionary phases than to expansionary phases, which is consistent with the view that economies tend to become more synchronized during recessions than during expansions. However, notice that the degree of centrality also varies across nations. In particular, notice that some countries have become more central since the early 2000s, as is the case of Brazil, Chile, South Africa, Singapore, Hong Kong, Belgium, Netherlands and Australia, indicating an increasing importance in the propagation of global business cycle shocks associated to these economies.

We also compute the average centrality across countries, which can be interpreted as a global measure of the transmission of business cycle shocks. We define the global centrality as,

$B_{t}=\frac{\sum_{i} B_{i, t}}{n}$,

where $B_{i, t}$ is the time-varying betweenness centrality and $n$ is the number of countries. The global centrality is plotted in Fig. 10 and

Table 2

Harris-Tzavalis unit-root test.

\begin{tabular}{ll}
\hline & $(1)$ Test statistic (p-value) \\
\hline Business cycle synchronization & $0.7529(0.0433)$ \\
Financial openness & $0.8566(1.0000)$ \\
Human capital index diff. & $0.9543(1.0000)$ \\
Bilateral trade & $0.7623(0.3276)$ \\
Liquid liabilities to GDP diff. & $0.7231(0.0000)$ \\
Financial system deposit to GDP diff. & $0.7715(0.7846)$ \\
Capital stock per capita diff. & $0.9263(1.0000)$ \\
Private credit to GDP diff. & $0.8458(1.0000)$ \\
Urban population diff. (\% of total population) & $0.9161(1.0000)$ \\
Difference of sectoral composition & $0.7304(0.0000)$ \\
Government expenditure (\% of GDP) diff. & $0.6627(0.0000)$ \\
\hline
\end{tabular}

Time trends are included in all the tests; p-values are presented in parentheses. provides similar information to the country-specific cases. Accordingly, it tends to increase during periods of global recessions, as defined by the probabilities of the unified Markov-switching model, reaching its maximum level during the Great Recession. Moreover, the level of global centrality experiences a significant increase around the early 2000s, implying a higher international business cycles connectedness, which increases the likelihood that countryspecific shocks are transmitted to the rest of the economies in the world. This result is consistent with the findings in the previous sections related to the increase in global business cycle interdependence.

\section{What does explain changes in synchronization?}

In Section 2.1, we document the existence of a gradual increase in global business cycle synchronization since the beginning of the 21st century. The clustering analysis presented in Section 2.2.1 also suggests that the increase in global business cycle synchronization is mainly driven by emerging economies. In this section, we identify the underlying factors explaining changes in pairwise business cycle interdependence by using a BMA approach to account for model uncertainty. Since there are different theories suggesting different potential determinants of business cycle synchronization, we are not certain about the true model specification governing business cycle co-movements. The BMA approach allows us to deal with that uncertainty. To the best of our knowledge, this is the first study to address model uncertainty in the identification of the main drivers of business cycle interdependence over time.

\subsection{Data}

Previous studies in the literature have obtained different results depending on the data, methodology, and variables considered. However, at least three factors are considered in most empirical studies on business cycle co-movement: international trade, specialization, and financial factors. In addition to these standard potential determinants, we follow Baxter and Kouparitsas (2005) and include factor endowments into our analysis. We also propose as a new potential determinant common fiscal policy. We focus on explaining changes in business cycle interdependence based on within-variation across time; thus, we consider only time-varying factors. The data are collected for the 1981-2010 period at an annual frequency. ${ }^{14}$ We describe in details the measurement of the potential determinants as follows:

- International trade. In theory, trade positively affects business cycle synchronization, as shocks are transmitted between countries through their trade flows. This positive relationship between trade and business cycle co-movement is predicted by a number of theoretical models, such as those of Canova and Dellas (1993) and Kose and Yi $(2001,2006) .{ }^{15}$ This trade channel is captured in our analysis by including the bilateral trade measure used in Frankel and Rose (1998),

$$
T_{a b, t}=\frac{E_{a, b, t}+I_{a, b, t}}{G D P_{a, t}+G D P_{b, t}}
$$

where $E_{a, b, t}$ denotes total exports from country $a$ to country $b$ in year $t, I_{a, b, t}$ denotes imports to country $a$ from country $b$ in

\footnotetext{
14 Definitions for all the variables are provided in Appendix E.

15 Evidence of the positive relationship between trade intensity and business cycle synchronization is found in Frankel and Rose (1998), Imbs (2004), Baxter and Kouparitsas (2005), and Calderon et al. (2007), among others.
} 
year $t$, and $G D P_{a, t}$ is the nominal GDP in country $a$ in year $t$. Bilateral trade data are taken from the IMF's Direction of Trade Statistics. ${ }^{16}$

- Specialization. Similarity in industrial composition proxies for the specialization patterns in both countries. We expect two economies with a similar sectoral composition to have high business cycle interdependence since sector-specific shocks could be rapidly transmitted from one economy to the other (Imbs, 2004).

To capture differences in the sectoral composition between two countries, we use agriculture, industry, and services real value added, and following the computation in Imbs (2004):

$S_{a b, t}=\sum_{k=1}^{n}\left|S_{a, t}^{k}-S_{b, t}^{k}\right|$

where $S_{a, t}^{k}$ is the GDP share of sector $k$ in country $a$ during period $t$. This index takes a value from 0 (completely similar structures) to 2 (completely different structures). ${ }^{17}$

- Financial factors: financial openness, private credit issued by deposit money banks and other financial institutions to GDP, financial system deposits to GDP, and liquid liabilities to GDP. These variables proxy for financial integration.

In theory, the effect of financial integration on business cycle synchronization is ambiguous and depends on the transmission mechanism of the shocks. In periods of high financial integration, negative shocks to firm productivity in a particular country will induce banks to decrease lending in these countries but increase lending in unaffected countries (Morgan et al., 2004), which may have a negative effect on the business cycle synchronization of these economies. On the other hand, a negative shock to the banking sector may be transferred to the other countries, since banks will reduce lending globally to shrink their balance sheets because of their lower net worth, thereby increasing business cycle comovement (Morgan et al., 2004), (Kalemli-Ozcan et al., 2013b).

As a measure of financial openness, we use

$F_{a b, t}=\frac{A_{a, t}+L_{a, t}}{G D P_{a, t}}+\frac{A_{b, t}+L_{b, t}}{G D P_{b, t}}$

where $A_{a, t}$ is total assets to GDP and $L_{a, t}$ is liquid liabilities to GDP in country $a$.

For private credit to GDP, financial system deposits to GDP and liquid liabilities to GDP, we transform the variables to capture dissimilarities between two countries, $a$ and $b$, since we aim to explain de-synchronization among countries, $\gamma_{t}^{a, b}$, as defined in Eq. (12). In particular, we compute the absolute value of the difference in financial factor $x$ between country $a$ and country $b$.

$x_{a b, t}=\left|x_{a, t}-x_{b, t}\right|$

where $x_{a, t}$ is a financial variable in country $a$ at period $t$ and $x_{b, t}$ is the same financial variable in country $b$ at the same time period, $t$.

- Factor endowments. We consider two main factors of production: labor, proxied by human capital and the proportion

\footnotetext{
16 For robustness, we also use the trade intensity measure in Deardorff (1998). The results of the analysis using this alternative measure of bilateral trade intensity remain quantitatively unchanged and are available upon request.

17 Agriculture, service, and industrial value added are taken from the World Development Indicators.
}

of a country's population living in urban areas, and capital, proxied by the per capita capital stock. As Baxter and Kouparitsas (2005) pointed out, economic theories, including the standard Heckscher-Ohlin theory and Ricardian theories, predict a relationship between factor endowments, trade and business-cycle co-movements.

Human capital proxies for skilled and unskilled labor. Dellas and Sakellaris (2003) find that schooling is countercyclical owing to higher opportunity cost during expansions. These higher costs lead to substitution between human capital investment and competing economic activities. Thus, we expect similarities in human capital indexes between two countries to be associated with higher business cycle comovement. ${ }^{18}$ The proportion of a country's population living in urban areas also captures different labor skills. ${ }^{19}$

We use the absolute value of the difference in endowment factors, $z$, to capture dissimilarities in factors of production between country $a$ and country $b$ at period $t$,

$z_{a b, t}=\left|z_{a, t}-z_{b, t}\right|$

where $z_{a, t}$ is a factor endowment in country $a$ at $t$ and $z_{b, t}$ is the same factor endowment in country $b$ at the same period $t$.

- Common fiscal policy. The Eurozone sovereign debt crisis that started in Greece at the end of 2009 and subsequently spread to Ireland, Portugal and Spain suggests that two economies with high level of debts and fiscal deficit are more likely to be in recession than two economies that diverge in their level of debt or deficit. Thus, we consider as an additional potential determinant of business cycle synchronization dissimilarities in fiscal policy. We measure this dissimilarity using the absolute value of the difference in government expenditure (share of GDP) between two countries.

In the next section, we briefly present the BMA approach used to infer the most robust factors correlated with business cycle interdependence.

\subsection{Methodology}

To address model uncertainty and unobserved time-invariant pairwise factors, we use a BMA panel data approach. The pairwise de-synchronization model is defined as

$\gamma_{a b, t}=x_{a b, t}^{\prime k} \beta^{k}+\eta_{a b}+\mu_{t}+v_{a b, t}$,

where $\gamma_{a b, t}$ is the distance or de-synchronization between the business cycle of countries $a$ and $b$, and $x_{a b, t}^{\prime k}$ includes a set of potential determinants, as described in Section 3.1. The pairwise country fixed effects, $\eta_{a b}$, capture time-invariant unobservable factors in both countries.

We examine the stationary properties of our determinants by using the Harris and Tzavalis (1999) unit-root test to avoid spurious inference. ${ }^{20}$ Table 2 shows that our main variable of interest, business cycle de-synchronization, follows a unit root process, for some panels, at the $1 \%$ significance level. Other variables, such as financial

\footnotetext{
18 We take the log of the human capital index before computing the absolute difference. The other determinants are expressed in percentages; thus, we use the direct differences.

19 Urban population is also highly correlated with the level of income of a country (Bloom et al., 2008). Differences in urban population could also capture different levels of economic development.

20 This test assumes that the number of periods, $T$, is small and that the number of panels, $N$, is large. The main shortcoming of this test is that it imposes the same autoregressive parameter on all the panels.
} 
Table 3

Determinants of business cycle de-synchronization: a BMA approach. Hyper-g-prior. Static panel. Period: 1984-2010.

\begin{tabular}{|c|c|c|c|c|c|}
\hline & PI prob. & Pt. mean & Pt. Std. & Sign & t-Stat. \\
\hline Government expenditure (\% of GDP) & 0.9883 & 0.0135 & 0.004 & 1 & 3.3461 \\
\hline Human capital index diff. & 0.9668 & 0.1811 & 0.0723 & 1 & 2.5027 \\
\hline Financial openness & 0.9493 & 0.0232 & 0.0104 & 1 & 2.2241 \\
\hline Liquid liabilities to GDP diff. & 0.8975 & -0.0096 & 0.0055 & 0 & -1.7501 \\
\hline Bilateral trade & 0.8957 & -1.0936 & 0.6289 & 0 & -1.7391 \\
\hline Urban population diff. (\% of total population) & 0.5919 & -0.0325 & 0.0512 & 0 & -0.6349 \\
\hline Financial system deposit to GDP diff. & 0.5184 & 0.0005 & 0.002 & 0.94 & 0.2346 \\
\hline Capital stock per capita diff. & 0.5106 & 0.0000 & 0.0000 & 0.0000 & -0.2011 \\
\hline Private credit to GDP diff. & 0.5059 & 0.0000 & 0.0025 & 0.9256 & 0.007 \\
\hline Difference of sectoral composition & 0.5047 & -0.0011 & 0.0104 & 0.0014 & -0.1014 \\
\hline
\end{tabular}

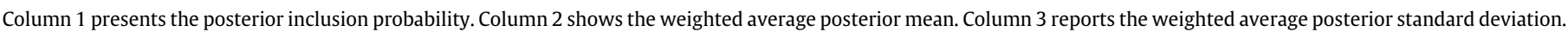

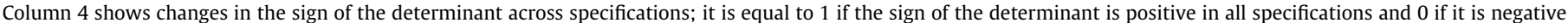

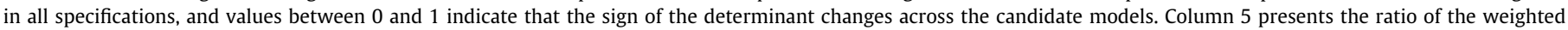

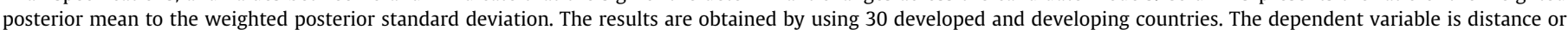

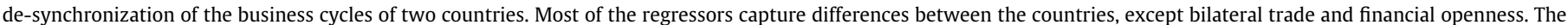

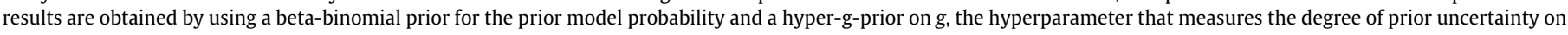
coefficients.

openness, bilateral trade, differences in human capital, capital stock per capita, financial deposit to GDP, private credit to GDP, and urban population, also present a unit root. Therefore, we use the firstdifference transformation to eliminate the pairwise country fixed effects. Unobserved common factors are captured in $\mu_{t}$ and are eliminated by cross-sectionally demeaning the data.

The key question is as follows: Which variables $x_{a b, t}^{\prime k}$ should be incorporated into the model? BMA addresses model uncertainty by estimating models for all possible combinations of the regressors and by taking a weighted average over all the candidate models, where the weights are determined by Bayes' rule. The probability that model $j, M_{j}$, is the "true" model given the data, $y$, i.e., the posterior model distribution given a prior model probability, is defined as

$$
P\left(M_{j} \mid y\right)=\frac{P\left(y \mid M_{j}\right) P\left(M_{j}\right)}{\sum_{i=1}^{2^{k}} P\left(y \mid M_{i}\right) P\left(M_{i}\right)}
$$

where $P\left(y \mid M_{j}\right)$ is the marginal likelihood of model $j, P\left(M_{i}\right)$ is the prior model probability, and $\sum_{i=1}^{2^{k}} P\left(y \mid M_{i}\right) P\left(M_{i}\right)$ is the integrated likelihood of model $j$. We consider an estimation framework with a Bayesian linear regression and a Zellner's g-prior structure for the regression coefficients. In particular, we assume a hyper-g-prior on $g$, the hyperparameter that measures the degree of prior uncertainty on coefficients. ${ }^{21}$ The advantage of using a mixture of g-priors, such as the hyper-g prior, is that the hyperparameter $g$ is not fixed across all the candidate models, but it is adjusted by using Bayesian updating. Recently, Ley and Steel (2012) have shown that hyper-g-prior outperforms fixed g-priors. We also need to specify a prior on the model space, $P(M)$. Following Ley and Steel (2009), we used the beta-binomial prior for the prior model probability, as it reduces the effect of imposing a particular prior model size on the posterior probabilities. This prior only requires the selection of the prior expected model size. ${ }^{22}$

\footnotetext{
21 For a detailed discussion of the use of Zellner's g-prior and the hyper-g-prior, see Ley and Steel (2012).

22 For robustness, we consider two additional priors for the model space: the binomial and uniform priors. Furthermore, we present robustness check for different forms of the hyperparameter $g$. In particular, we use the unit information prior (UIP), which set $g$ equal to the number of observations for all models. Results available in Fig. 1 of Appendix F, show that the determinants are robust to the model prior specification and to the hyperparameter $g$ form.
}

We are interested in the posterior inclusion probability (PIP) of a variable $h$, which is defined as

$P\left(\theta_{h} \neq 0 \mid y\right)=\sum_{\theta_{h} \neq 0} P\left(M_{k} \mid y\right)$

where $\theta_{h}$ contains the coefficients of the regressor set that defines model $h$ according to Eq. (27). The PIP is interpreted as the probability that a particular variable $h$ belongs to the true pairwise business cycle de-synchronization model.

\subsection{Results}

Because of data limitations regarding the factors described in Section 3.1, we restrict our analysis to a smaller set of countries. Table 3 reports the main determinants of changes in business cycle de-synchronization obtained by using the BMA panel approach over the 1984-2010 period for 30 developed and developing countries. ${ }^{23}$ Column 1 presents the posterior inclusion probability of each potential time-varying determinant of business cycle de-synchronization. We find that the most robust determinants are differences in government expenditure shares, differences in human capital, financial openness, differences in liquid liabilities shares and bilateral trade.

Although we cannot claim any causal relationship between these determinants and business cycle de-synchronization, because of simultaneity bias and reverse causality, we find that all these determinants affect business cycle de-synchronization with the expected sign (see the posterior mean in column 2 of Table 3 ). Financial integration is positively related to business cycle de-synchronization. This result is consistent with the recent empirical findings by Kalemli-Ozcan et al. (2013a) showing that cross-border banking integration between two countries is negatively related to co-movement of output. Negative shocks to the real sector of one economy decrease bank lending in the affected countries and increase lending in the unaffected economies, increasing the divergence in business cycles

\footnotetext{
23 Some of the determinants were not available over the whole sample period for some countries. To avoid losing other determinants, we excluded the countries for which the determinant was missing for a particular period from the sample. These countries are Hong Kong, Taiwan, Luxembourg, Germany, Greece, Belgium, Iraq, Romania, Venezuela, Chile, Bulgaria, China, and the United Kingdom. We lost years 1981, 1982, and 1983 because of the first differences transformation to get rid of the pairwise fixed effects and the inclusion of two lags of the dependent variable in the dynamic panel model.
} 
Table 4

Determinants of business cycle de-synchronization: a BMA approach. Hyper-g-prior. Dynamic panel. Period: 1984-2010.

\begin{tabular}{|c|c|c|c|c|c|}
\hline & PI prob. & Pt. mean & Pt. Std. & Sign & t-Stat. \\
\hline De-synchronization $_{t-1}$ & 1 & 0.1779 & 0.0095 & 1 & 18.8249 \\
\hline De-synchronization $_{t-2}$ & 1 & -0.2078 & 0.0096 & 0 & -21.5438 \\
\hline Government expenditure (\% of GDP) & 0.9906 & 0.0148 & 0.0042 & 1 & 3.5641 \\
\hline Human capital index diff. & 0.9836 & 0.2441 & 0.0745 & 1 & 3.274 \\
\hline Financial openness & 0.8231 & 0.0223 & 0.0135 & 1 & 1.6505 \\
\hline Liquid liabilities to GDP diff. & 0.7041 & -0.0083 & 0.0067 & 0 & -1.2493 \\
\hline Bilateral trade & 0.4322 & -0.4747 & 0.6568 & 0 & -0.7227 \\
\hline Urban population diff. (\% of total population) & 0.1911 & -0.0124 & 0.0365 & 0 & -0.3402 \\
\hline Difference of sectoral composition & 0.143 & -0.0014 & 0.0068 & 0.001 & -0.2069 \\
\hline Private credit to GDP diff. & 0.1365 & -0.0002 & 0.0015 & 0.0002 & -0.1464 \\
\hline Financial system deposit to GDP diff. & 0.1322 & 0.0000 & 0.0011 & 0.7464 & -0.0358 \\
\hline Capital stock per capita diff. & 0.1225 & 0.0000 & 0.0000 & 0.0000 & -0.0294 \\
\hline
\end{tabular}

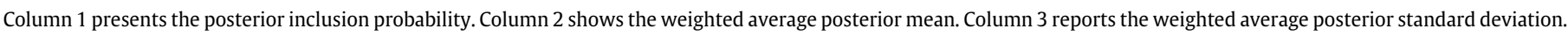

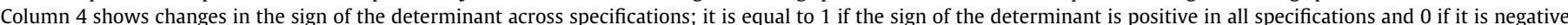

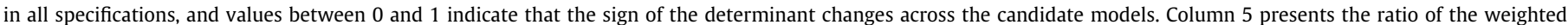

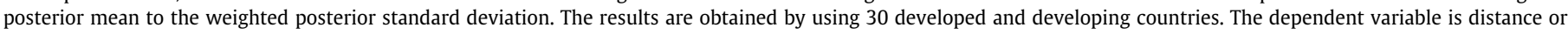

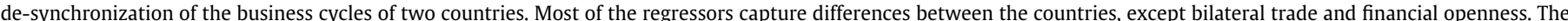

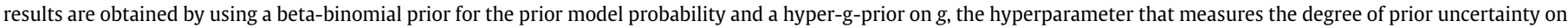
coefficients.

between affected and unaffected countries. This result suggests that during our period of analysis, negative shocks to firm productivity dominate shocks to the banking sector, which is plausible since a major banking crisis only occurred during the last few years of our sample, from 2007 to 2009. Human capital index is a factor endowment considered by Baxter and Kouparitsas (2005), who found that schooling is not a robust factor of business cycle co-movement. In contrast to their study, we find that countries with different levels of schooling are more likely to be in different business cycle phases. Our human capital indexes mainly measure the number of enrollments in high school and tertiary education. In periods of expansion, individuals tend to substitute human capital investment with other economic activities because of the higher opportunity costs of schooling. Therefore, countries with different levels of schooling are more likely to be in different business cycle phases. Human capital can also capture different levels of economic development. The high posterior inclusion probability of bilateral trade is consistent with previous studies in the literature showing how productivity, fiscal, and other real shocks are transmitted through trade; increasing the synchronization of economies across borders (Baxter and Kouparitsas (2005), Frankel and Rose (1998), Imbs (2004), among many others). Finally, our study is the first to document the importance of common fiscal policy (government expenditure share of GDP) as a robust determinant of changes in business cycle synchronization. If countries experience similar increases in government purchases or decrease in taxes, they tend to be associated with similar business cycle fluctuations.

Table 4 presents the results of the BMA in a dynamic panel setting that includes two lags of the de-synchronization index as regressors. The number of lags was selected according to the posterior inclusion probability criteria. ${ }^{24}$ The results show that the main determinants of business cycle interdependence are robust to the inclusion of a lagged dependent variable. The exceptions are liquid liabilities and bilateral trade, both have a lower posterior inclusion probability, 0.70 and 0.43 , respectively.

As we show in Fig. 6, global business cycle interdependence has experienced a significant but gradual increase since the beginning of recent globalization era, early 2000s. To assess if the main determinants of business cycle interdependence have changed over time we split the sample into three periods, based on the occurrences of the global recessions as dated by the IMF. In particular, the three periods are: $1984-1993,1994-2003$ and $2004-2010 .^{25}$ In column 1 of Table 5 , we report the posterior inclusion probability obtained using the BMA panel analysis for the period 1984-1993. We find that the most robust determinants of business cycle synchronization during this period are liquid liabilities, bilateral trade, and differences in human capital indexes between the two countries. These results are very similar to those obtained by using the full sample period, 1984-2010. In the period 1994-2003 (see column 2, Table 5), we find that besides bilateral trade, differences in sectoral composition, differences in capital stock per capita, differences in government expenditure shares and financial openness become important robust correlated factors of business cycle synchronization.

Surprisingly, we find that during the recent globalization era (see column 3 of table 5), the only robust determinant is similarity in sectoral composition. Acemoglu et al. (2012) study the importance of sectoral composition in the formation of business cycles and show that in the presence of intersectoral input-output linkages, microeconomics idiosyncratic shocks may lead to aggregate fluctuations. In addition, Camacho and Leiva-Leon (2014) find evidence of a cascade effect in the transmission of sectoral business cycle shocks. At the aggregate level, if similarity in the sectoral composition of countries in the major world economies increases, business cycle shocks can be more rapidly transmitted from one country to another, increasing global business cycle interdependence. Overall, these results suggest that the gradual increase in global economic cycle interdependence since the early 2000s is highly associated with larger similarity in the sectoral composition of the main world economies.

\subsection{Robustness}

In this subsection, we check the robustness of the results obtained with the BMA to the assumptions made in the identification of the main drivers of business cycle interdependence. First, we present results for an analysis using different priors for the model probability and for the hyperparameter $g$; for the latter purpose, we adopt the BRIC prior introduced by Fernandez et al. (2001), which sets $g=\max \left(N, K^{2}\right)$. The results, presented in Fig. 1 of Appendix F, show that although the probabilities of inclusion are less conservative for the binomial model prior and for the beta binomial with the BRIC prior for the hyperparameter $g$, the main findings are robust to the specification of the model and hyperparameter priors. The most

\footnotetext{
24 We also consider specifications with a different number of lags of the desynchronization index, but the posterior inclusion probability of any additional lag
} was low.

\footnotetext{
25 The last four global recession are dated by the IMF as follows: 1980-1983, 1990 1993, 2001-2002, and 2008-2009.
} 
Table 5

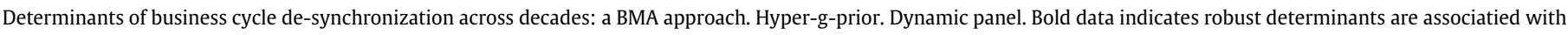
a posterior inclusion probability higher than 0.8 .

\begin{tabular}{|c|c|c|c|}
\hline & PI prob. 84-93 & PI prob. 94-03 & PI prob. $04-10$ \\
\hline De-synchronization $_{t-1}$ & 1 & 1 & 1 \\
\hline De-synchronization $_{t-2}$ & 1 & 1 & 1 \\
\hline Bilateral trade & 0.9340 & 0.8174 & 0.4651 \\
\hline Human capital index diff. & 0.9231 & 0.4296 & 0.5359 \\
\hline Liquid liabilities to GDP diff. & 0.8272 & 0.4475 & 0.1614 \\
\hline Financial openness & 0.3647 & 0.9980 & 0.2383 \\
\hline Private credit to GDP diff. & 0.2533 & 0.4904 & 0.1617 \\
\hline Financial system deposit to GDP diff. & 0.1986 & 0.3603 & 0.1735 \\
\hline Government expenditure (\% of GDP) & 0.1771 & 1 & 0.2312 \\
\hline Capital stock per capita diff. & 0.1484 & 0.8740 & 0.1965 \\
\hline Difference of sectoral composition & 0.1474 & 0.9704 & 0.9701 \\
\hline Urban population diff. (\% of total population) & 0.1415 & 0.5234 & 0.1950 \\
\hline
\end{tabular}

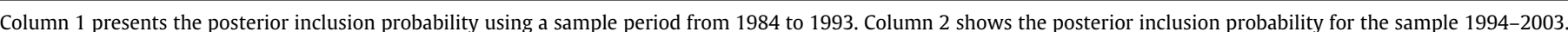

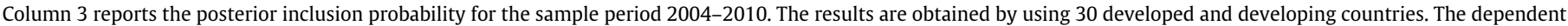

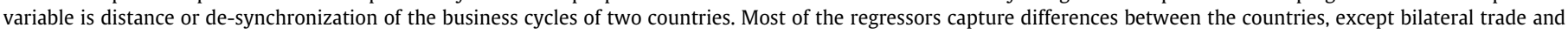

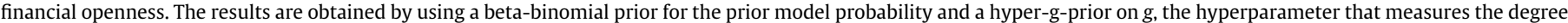
of prior uncertainty on coefficients.

robust determinants of fluctuations in business cycle synchronization, in the dynamic model, are the same regardless of the model and hyperparameter priors. The only exception is that the posterior inclusion probabilities of financial openness are significantly lower for the binomial probability model prior and for the beta binomial model prior assuming BRIC prior for the hyperparameter $g$.

Second, we also check the robustness of our results to use of the Bayesian model averaging technique adopted in the main analysis. In particular, to identify the main determinants of changes in business cycle interdependence, we consider a Bayesian combination of frequentist estimators, the weighted-average least squares (WALS) method introduced by Magnus et al. (2010). The WALS estimator relies on an orthogonalization of the regressors such that they are independent from one another. This orthogonal transformation allows us to consider prior distributions that are more consistent with our ignorance regarding the importance of each potential determinant in explaining business cycle interdependence and substantially reduces the computational time of this model-averaging technique. The results presented in Table I and Table II of Appendix F show that the main determinants found using the WALS method are the same as the determinants obtained by using the BMA approach. As a rule of thumb, a determinant is considered robust using the WALS estimator if the t-statistics is above 2 in absolute value. Therefore, our results are robust to the use of different model and hyperparameter $g$ priors and to the model averaging technique.

\subsection{Sectoral composition and global interdependence}

The findings of the BMA reported in Table 5 show that the determinants of business cycle interdependence vary across time. In particular, we find that during the period 2000-2010, the only robust factor explaining variation in business cycle interdependence is common sectoral composition.

To understand which is the sector that contributed the most to explain variation in business cycle synchronization, we divide dissimilarity of sectoral composition into three different subcomponents: difference in agriculture share, difference in industry share, and difference in service share. Furthermore, we separate pairs of countries that experienced an increasing synchronization from pairs of countries that presented a relatively time invariant business cycle synchronization over the full sample period. In order to group pairs of countries based on common temporal patterns in business cycle synchronization we use the K-Spectral Centroid (K-SC) clustering algorithm (Yang and Leskovec, 2011), which is designed to cluster time series by their shape. The top panels of Fig. 11 present the pairwise business cycle synchronizations, $\delta_{t}^{a, b}$, for the two different groups identified with the K-SC algorithm, i.e. the "Increasing Sync" group and "Stable Sync" group. ${ }^{26}$ One third of all the pairs of countries was allocated to the Increasing Sync group, while the rest of pairs were assigned to the Stable Sync group. The increase in business cycle synchronization since 2000 in the Increasing Sync group confirms the gradual increase in global business interdependence found in Section 2.1 (see Fig. 11a). The bottom panels of Fig. 11 show the differences in the disaggregated sectoral composition, i.e. agricultural, industrial, and services, only for the pairs of countries in the Increasing Sync group. The results show that differences in agricultural composition (see Fig. 11c) decreased significantly since the late 90s. This decrease has been accompanied by an increased in global business cycle synchronization. On the other hand, the differences in the industrial composition have slightly increased from 1995 to 2003 while the differences in services composition remained relatively stable over the sample period, 1981-2010. ${ }^{27}$

Overall, the empirical analysis shows: i) the existence of a gradual increase in global business cycle synchronization lead by a third of all the pairs of countries considered in our sample; ii) the increase of the global business cycle synchronization is mainly associated to emerging market economies, since they became more synchronized with the rest of the world; and iii) the main robust factor explaining variation in business cycle synchronization during 2004-2010, the period of highest increase in business cycle synchronization, is sectoral composition differences between countries.

\section{Conclusion}

The first part of this paper provides a comprehensive examination of the evolution of business cycle co-movement across 43 developed and developing countries over the period from 1981 to 2013. We apply a novel Markov-switching model to infer the probability that two countries are in the same business cycle phase. This approach accounts for the non-linearity inherent to the dynamics of business cycles. The results show that most of the economies have become more synchronized since the recent globalization era (i.e., from 2000 onward), suggesting that systemic risk has increased during the last decade. This result is also validated under an integrated perspective with a proposed nonlinear dynamic factor model.

\footnotetext{
26 In Fig. 11 the time series are stacked showing the relative contribution of each element at time $t$.

27 Providing an explanation about the mechanism by which sectoral composition, in particular agricultural, strongly influences synchronization of cycles would require a more structural analysis, such as a DSGE modeling approach, which is out of the scope of this paper and therefore left for further research.
} 


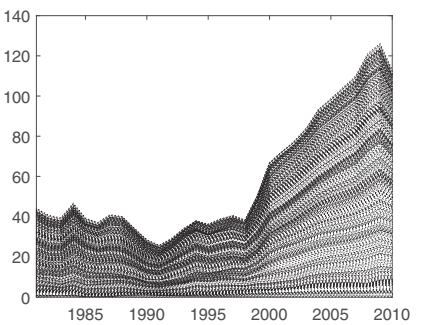

(a) Increasing Synch. group

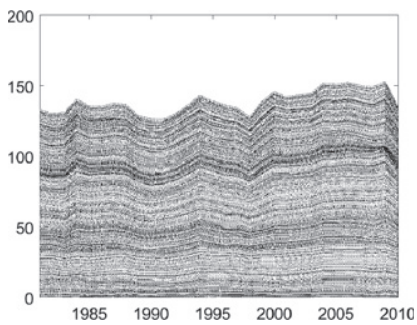

(b) Stable Synch. group

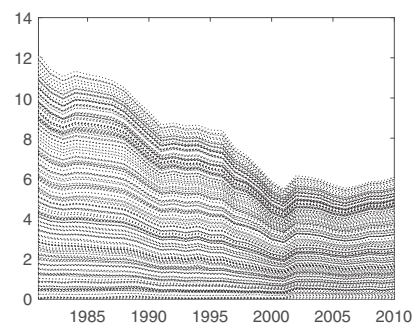

(c) Agriculture

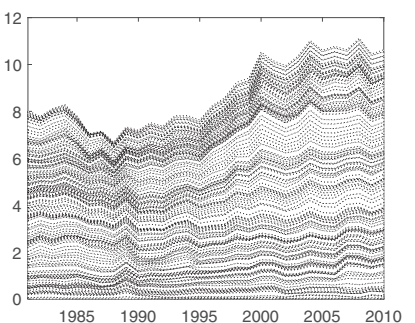

(d) Industry

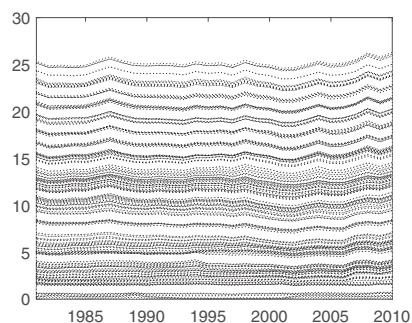

(e) Service

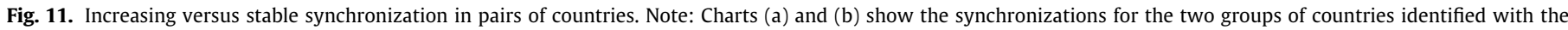
K-Spectral Centroid algorithm. Charts (c), (d) and (e) show the differences in agriculture, industry and services, respectively, as shares of GDP for increasing sync. countries.

Next, we consider a clustering analysis to evaluate whether there are groups of countries with similar patterns in business cycle comovement. The clustering analysis reveals at least four groups of countries that are relatively stable over time: the Euro area cluster, the Anglo-Saxon cluster, the Asian Tigers cluster, and the emerging markets cluster. Moreover, the increase in synchronization after 2000 seems to be mainly attributed to the increased synchronization of the emerging markets cluster with the rest of the major world economies. We also consider network measures to quantify the degree of synchronization of one economy with the other economies in the world. The network analysis shows that the degree of connectedness of a country with the other countries in the world tends to increase in periods prior to recessions. These findings have important implications for policy makers, who could use the proposed framework to evaluate the degree of exposure that a given country has to external shocks.

The second part of the paper focuses on identifying the most important factors explaining variation in business cycle comovement. As there is no agreement in the business cycle literature about the potential determinants of business cycle synchronization, we rely on a Bayesian model averaging approach to account for model uncertainty. The results suggest that the most robust determinants are financial openness, government expenditure, and human capital. Other important factors that explain changes in business cycle co-movement are bilateral trade and liquid liabilities. However, the importance of these determinants, measured by their inclusion probability, varies across time. In particular, we find that the only robust determinant after the increase in global business cycle interdependence (2004-2010) is similarity in countries' industrial composition.

\section{Appendix A. Supplementary data}

Supplementary data related to this article can be found online at http://dx.doi.org/10.1016/j.jinteco.2016.07.003.

\section{References}

Acemoglu, D., Carvalho, V.M., Ozdaglar, A., Tahbaz-Salehi, A., 2012. The network origins of aggregate fluctuations. Econometrica 80 (5), 1977-2016.

Altug, S., Canova, F., 2012. Do institutions and culture matter for business cycles? Open Econ. Rev. 25 (1), 1-30.

Barnett, W.A., Chauvet, M., Leiva-Leon, D., 2016. Real-time nowcasting nominal GDP under structural breaks. J. Econ. 191 (2), 312-324.

Baxter, M., Kouparitsas, M.A., 2005. Determinants of business cycle comovement: robust analysis. J. Monet. Econ. 52 (1), 113-157.

Bloom, D.E., Canning, D., Fink, G., 2008. Urbanization and the wealth of nations. Science 319 (5864), 772-775.

Burns, A., Mitchell, W., 1946. Measuring business cycles. Nat. Bur. Econ. Res. 109-111. Calderon, C., Chong, A., Stein, E., 2007. Trade intensity and business cycle synchronization: are developing countries any different? J. Int. Econ. 71 (1), 2-21.

Camacho, M., Leiva-Leon, D., 2014. The propagation of industrial business cycles. Bank of Canada Working Paper 2014-48,

Camacho, M., Perez-Quiros, G., Saiz, L., 2008. Do European business cycles look like one? J. Econ. Dyn. Control. 32 (7), 2165-2190.

Canova, F., Ciccarelli, M., 2012. ClubMed? Cyclical fluctuations in the Mediterranean basin. J. Int. Econ. 88 (1), 162-175.

Canova, F., Dellas, H., 1993. Trade interdependence and the international business cycle. J. Int. Econ. 34 (1), 23-47.

Canova, F., Schlaepfer, A., 2013. Has the EuroMediterranean partnership affected Mediterranean business cycles? J. Appl. Econ. http://dx.doi.org/10.1002/jae.2364

Clark, T.E., Van Wincoop, E., 2001. Borders and business cycles. J. Int. Econ. 55 (1), 59-85.

Deardorff, A., 1998. Determinants of bilateral trade: does gravity work in a neoclassical world? In: Frankel, J. (Ed.), The Regionalization of the World Economy. The University of Chicago Press, Chicago.

Del Negro, M., Otrok, C., 2008. Dynamic factor models with time-varying parameters: measuring changes in international business cycles. Fed. Reserve Bank N. Y. Staff Rep. 326.

Dellas, H., Sakellaris, P., 2003. On the cyclicality of schooling: theory and evidence. Oxf. Econ. Pap. 55 (1), 148-172.

Doyle, B.M., Faust, J., 2005. Breaks in the variability and comovement of G-7 economic growth. Rev. Econ. Stat. 87 (4), 721-740.

Efron, B., Halloran, E., Holmes, S., 1996. Bootstrap confidence levels for phylogenetic trees. Proc. Natl. Acad. Sci. U.S.A. 93, 13429-13434.

Fernandez, C., Ley, E., Steel, M.F.J., 2001. Benchmark priors for Bayesian model averaging. J. Econ. 100, 381-427.

Forni, M., Gambetti, L., 2010. Macroeconomic shocks and the business cycle: evidence from a structural factor model. CEPR Discussion Paper No. DP7692.

Frankel, J.A., Rose, A.K., 1998. The endogeneity of the optimum currency area criteria. Econ. J 108 (449), 1009-1025.

Hamilton, J.D., 1994. Time Series Analysis (Vol. 2). Princeton University Press, Princeton. 
Harding, D., Pagan, A., 2006. Synchronization of cycles. J. Econ. 132 (1), 59-79.

Harris, R.D.F., Tzavalis, E., 1999. Inference for unit roots in dynamic panels where the time dimension is fixed. J. Econ. 91, 201-226.

Imbs, J., 2004. Trade, finance, specialization, and synchronization. Rev. Econ. Stat. 86 (3), 723-734.

Imbs, J., 2006. The real effects of financial integration. J. Int. Econ. 68 (2), 296-324.

Kalemli-Ozcan, S., Papaioannou, E., Perri, F., 2013. Global banks and crisis transmission. J. Int. Econ. 89 (2), 495-510.

Kalemli-Ozcan, S., Papaioannou, E., Peydr, J.L., 2013. Financial regulation, financial globalisation, and the synchronization of economic activity. J. Financ. 68 (3), 1179-1228.

Kim, C.J., Nelson, C.R., 1999. State-space Models With Regime Switching. The MIT Press.

Koop, G., Korobilis, D., 2014. A new index of financial conditions. Eur. Econ. Rev. 71, 101116.

Kose, M.A., Otrok, C., Prasad, E., 2012. Global business cycles: convergence or decoupling? Int. Econ. Rev. 53 (2), 511-538.

Kose, M.A., Otrok, C., Whiteman, C.H., 2003. International business cycles: world, region, and country-specific factors. Am. Econ. Rev. 93 (4), 1216-1239.

Kose, M.A., Yi, K.M., 2001. International trade and business cycles: is vertical specialization the missing link? Am. Econ. Rev. 91 (2), 371-375.

Kose, M.A., Yi, K.M., 2006. Can the standard international business cycle model explain the relation between trade and comovement? J. Int. Econ. 68 (2), 267-295.
Leiva-Leon, D., 2016. Measuring Business Cycles Intra-Synchronization in US: A Regime-Switching Interdependence Framework. Oxford Bulletin of Economics and Statistics 2014-2038. (forthcoming).

Ley, E., Steel, M.F., 2009. On the effect of prior assumptions in Bayesian model averaging with applications to growth regression. J. Appl. Econ. 24 (4), 651-674.

Ley, E., Steel, M.F., 2012. Mixtures of g-priors for Bayesian model averaging with economic applications. J. Econ. 171 (2), 251-266.

Magnus, J.R., Powell, O., Prüfer, P., 2010. A comparison of two model averaging techniques with an application to growth empirics. J. Econ. 154 (2), 139-153.

Morgan, D.P., Rime, B., Strahan, P.E., 2004. Bank integration and state business cycles. Q. J. Econ. 119 (4), 1555-1584.

Rose, A., Engel, C., 2002. Currency unions and international integration. J. Money Credit Bank. 34, 1067-1089.

Sala-i Martin, X., Doppelhofer, G., Miller, R.I., 2004. Determinants of long-term growth: a Bayesian averaging of classical estimates (BACE) approach. Am. Econ. Rev. 94 (4), 813-835.

Shimodaira, H., 2002. Assesing the uncertainty of the cluster analysis using the bootstrap resampling. Proceedings of the Institute of Statistical Mathematics. pp. 33-44.

Yang, J., Leskovec, J., 2011. Patterns of temporal variation in online media. Proceedings of the Fourth ACM International Conference on Web Search and Data Mining. pp. 177-186. 